\title{
Review of the Japanese Species of Conchapelopia (Insecta: Diptera: Chironomidae), with Keys to the Known Males and Pupae
}

\author{
Hiromi Niitsuma \\ Department of Biology, Faculty of Education, Shizuoka University, \\ 836 Ôya, Suruga-ku, Shizuoka, 422-8529 Japan \\ E-mail: edhniit@ipc.shizuoka.ac.jp
}

(Received 1 March 2007; Accepted 26 December 2007)

\begin{abstract}
The Japanese species of the chironomid midge genus Conchapelopia Fittkau, 1957 are reviewed based on a study of the type material and/or recently obtained specimens. The following eight species are recognized as valid: $C$. japonica (Tokunaga, 1937); C. amamiaurea Sasa, 1990; C. okisimilis Sasa, 1990; C. shikotuensis Sasa, 1990; C. unzenalba Sasa, 1991; C. togamaculosa Sasa and Okazawa, 1992; C. togapallida Sasa and Okazawa, 1992; and C. seiryusetea Sasa, Suzuki, and Sakai, 1998. The male and female imagines of Conchapelopia japonica and C. shikotuensis, and the male imagines of C. okisimilis, C. togamaculosa, and C. togapallida are redescribed, while the immature stages of these species and the female imagines of the latter three species are described for the first time. Reexamination of the holotypes of Conchapelopia amamiaurea, C. unzenalba, and C. seiryusetea has shown that the respective original descriptions contain errors in some diagnostic aspects, which are corrected in this study. Seven previously described taxa are found to be synonyms. Keys to male imagines and pupae of known Japanese species of Conchapelopia are included.
\end{abstract}

Key Words: Insecta, Diptera, Chironomidae, Tanypodinae, Conchapelopia, taxonomy, synonym, Japan.

\section{Introduction}

The chironomid genus Conchapelopia Fittkau, 1957 belongs to the subfamily Tanypodinae and has a nearly worldwide distribution. Some 30 species have been recorded from the Northern Hemisphere (Oliver et al. 1990; Sæther et al. 2000; Chaudhuri et al. 2001; Michiels and Spies 2002). Seventeen nominal species are hitherto known from Japan (Sasa and Kikuchi 1995; Sasa 1998; Sasa and Suzuki 2001a, 2001b).

During the course of taxonomic studies on Chironomidae in Japan, I successfully raised Conchapelopia midges from larvae and pupae collected from many localities. Species of the genus are easily separable from one another primarily by the structure of the median volsella in the male hypopygium. The extensive material at hand has enabled me to compare various ontogenetic stages among many 
species and to assess additional potentially diagnostic characters in different stages. Here, I describe C. japonica (Tokunaga, 1937), C. okisimilis Sasa, 1990, C. shikotuensis Sasa, 1990, C. togamaculosa Sasa and Okazawa, 1992, and C. togapall$i d a$ Sasa and Okazawa, 1992 based on the male and female adults, pupae, and larvae. Descriptions of the immature stages of these species and the females of $C$. okisimilis, $C$. togamaculosa, and $C$. togapallida are given for the first time. Furthermore, reexamination of the holotypes of the three species $C$. amamiaurea Sasa, 1990, C. unzenalba Sasa, 1991, and C. seiryusetea Sasa, Suzuki, and Sakai, 1998 has revealed errors in some important diagnostic aspects of the original descriptions, which are corrected herein. This study has also demonstrated that several previously described taxa are synonymous, thus leaving just eight species recognized as valid in the Japanese fauna.

Most of the specimens examined are deposited in the collection of the Shizuoka University Museum (SUM). The holotypes of Conchapelopia amamiaurea, C. okisimilis, C. shikotuensis, C. unzenalba, C. togamaculosa, C. togapallida, and $C$. seiryusetea are now housed in the National Museum of Nature and Science, Tokyo (NSMT), all mounted on glass slides with gum-chloral medium. Measurements and counts are given as ranges, followed by means in parentheses. The terminology and abbreviations for general morphology follow Sæther (1980), with a few exceptions: the filamentous L-seta of the pupal abdomen and the b-seta of the larval maxillary palp are termed the lateral taenia and the b-sensillum, respectively (see Epler 2001) and the terminology for the cephalic setation of the larva conforms with that of Kowalyk (1985).

\section{Taxonomy}

Genus Conchapelopia Fittkau, 1957

[Japanese name: Torafu-yusurika zoku]

Conchapelopia Fittkau, 1957: 317. Type species: Tanypus pallidulus Meigen, 1818, by original designation.

Conchapelopia (Mesopelopia) Roback, 1971: 252. Type species: Conchapelopia (Mesopelopia) aleta Roback, 1971, by original designation and monotypy.

Emended diagnosis. Male. Antennal ratio 1.2-2.5. Thorax with 3-20 lateral antepronotals on each lobe. Middle leg with apically pointed or trifid tarsal claws. Tarsal beard moderately long in some species.

Female. Gonotergite IX well-developed, with a few setae in some specimens.

Pupa. Abdominal shagreen mainly consisting of bifid, multifid, or simple spinules. Abdominal segment VII with 3 or 4 pairs of lateral taeniae, segment VIII with 5 pairs of lateral taeniae. Abdominal segment VIII with spines $8-20 \mu \mathrm{m}$ long on posterolateral corners in some species.

Larva. Ventral cephalic seta $\mathrm{S}_{9}$ lateral or anterolateral to ventral sensory pore; $S_{10}$ posteromedial or anteromedial to $S_{9}$, and directly anterior or anteromedial to sensory pore.

Remarks. Generic diagnoses of Conchapelopia have been given by Fittkau (1957, 1962), Sæther (1977), Fittkau and Roback (1983), Fittkau and Murray (1986), 
Murray and Fittkau (1989), Epler (2001), and Michiels and Spies (2002). Although the Japanese species treated here are certainly referable to this genus, some of them have rather unusual features for the genus. Therefore, the generic diagnosis is emended to safely accommodate the Japanese species.

Conchapelopia shares many diagnostic features with Thienemannimyia Fittkau, 1957, Arctopelopia Fittkau, 1962, Rheopelopia Fittkau, 1962, Helopelopia Roback, 1971, Meropelopia Roback, 1971, Telopelopia Roback, 1971, Hayesomyia Murray and Fittkau, 1985, and Coffmania Hazra and Chaudhuri, 2000, which are all closely related to one another and form the Thienemannimyia group (Fittkau 1962; Roback 1971; Murray and Fittkau 1985; Hazra and Chaudhuri 2000). Males of Conchapelopia, together with those of the genera Arctopelopia, Helopelopia, Meropelopia, and Telopelopia, are distinguishable from those of the other genera, Thienemannimyia, Rheopelopia, Hayesomyia, and Coffmania, by the somewhat flattened and medially concave gonocoxite and the well-developed median volsella with dorsolateral processes. Within the Thienemannimyia group, a plastron plate occurs in the pupal thoracic horns in the genera Conchapelopia, Helopelopia, Meropelopia, Telopelopia, and Coffmania. Furthermore, a three-segmented b-sensillum occurs in the larval maxillary palpi in the genera Conchapelopia, Helopelopia, Rheopelopia, and Coffmania. Therefore, Helopelopia is considered to be most closely related to Conchapelopia, and indeed the former taxon was treated formerly as a subgenus of Conchapelopia by Roback $(1971,1981)$. Conchapelopia is, however, separated from Helopelopia by the lack of any setal tuft on abdominal tergite VIII in the adult male and the relatively robust basal segment (ratio of length to width 4.0 or less) of the maxillary palp in the larva. According to Fittkau and Roback (1983), Murray and Fittkau (1989), and Epler (2001), males of Helopelopia have a pair of prominent setal tufts on abdominal tergite VIII, and the larvae have a more slender basal segment (ratio of length to width 4.5-4.6) of the maxillary palp.

The Japanese species Conchapelopia togamaculosa has interesting pupal features, including the presence of an elliptical dark field on the thoracic median suture and relatively long L-setae on abdominal segments II-VI. These features were among those considered to be diagnostic of Helopelopia by Fittkau and Murray (1986), and they thus seem to further support a close relationship between Conchapelopia and Helopelopia.

Murray (1976) recognized the nepalicola species group, consisting of four Nepalese species, in Conchapelopia and noted (p. 301), "It is apparent, therefore, that the members of the nepalicola-group may form a distinct evolutionary line within the Thienemannimyia Series. It is possible that the group could be given generic status but whilst pupal and larval material is lacking it is preferable to include the group, at least provisionally, within an existing genus." This species group resembles representatives of the genus Hayesomyia rather than Conchapelopia s. str. in features of the male hypopygium: the gonocoxite is more or less cylindrical and the median volsella is distinctly bilobed without any dorsolateral process.

Among the known Japanese species referred to Conchapelopia, C. esakiana (Tokunaga, 1939) is most curious, since it has three median volsellae between the gonocoxites of the male hypopygium, rather than two as in its congeners, according to the original description (q.v.). It is possible that the taxon was founded on an aberrant specimen, although I have not seen the holotype. Conchapelopia gin- 
Table 1. Comparison of adult male characters in eight species of Conchapelopia.

\begin{tabular}{|c|c|c|c|c|c|c|}
\hline \multirow{2}{*}{ Species } & \multirow{2}{*}{$\begin{array}{l}\text { Antennal } \\
\text { ratio }\end{array}$} & \multirow{2}{*}{$\begin{array}{l}\text { Wing } \\
\text { markings }\end{array}$} & \multicolumn{2}{|c|}{ Leg } & \multicolumn{2}{|c|}{$\begin{array}{l}\text { Median volsella of } \\
\text { hypopygium }\end{array}$} \\
\hline & & & Markings & Tarsal brush & $\begin{array}{l}\text { Basolateral } \\
\text { corner }\end{array}$ & $\begin{array}{l}\text { Ventral } \\
\text { lobe }\end{array}$ \\
\hline C. japonica & $1.7-2.0$ & absent & absent & absent & $\begin{array}{l}\text { projecting } \\
\text { digitiformly }\end{array}$ & absent \\
\hline C. okisimilis & $1.5-1.7$ & absent & absent & absent & $\begin{array}{l}\text { projecting } \\
\text { triangularly }\end{array}$ & absent \\
\hline C. shikotuensis & $1.7-2.0$ & absent & $\begin{array}{l}\text { present on } \\
\text { Fe and Ti }\end{array}$ & absent & $\begin{array}{l}\text { projecting } \\
\text { digitiformly }\end{array}$ & absent \\
\hline C. togamaculosa & $1.8-2.0$ & present & absent & $\begin{array}{l}\text { present on } \\
\mathrm{Ta}_{3} \text { of } \mathrm{P}_{2}\end{array}$ & $\begin{array}{l}\text { projecting } \\
\text { triangularly }\end{array}$ & small \\
\hline C. togapallida & $1.2-1.6$ & absent & absent & absent & rounded & large \\
\hline C. amamiaurea & 1.7 & present & $\begin{array}{l}\text { present on } \\
\text { Fe and } \mathrm{Ti}\end{array}$ & $\begin{array}{l}\text { present on } \\
\mathrm{Ta}_{3} \text { of } \mathrm{P}_{2}\end{array}$ & $\begin{array}{l}\text { projecting } \\
\text { triangularly }\end{array}$ & absent \\
\hline C. unzenalba & 1.7 & absent & absent & $\begin{array}{l}\text { present on } \\
\mathrm{Ta}_{3} \text { of } \mathrm{P}_{2}\end{array}$ & $\begin{array}{l}\text { projecting } \\
\text { triangularly }\end{array}$ & ? present \\
\hline C. seiryusetea & 1.7 & absent & absent & $\begin{array}{l}\text { present on } \\
\mathrm{Ta}_{3} \text { of } \mathrm{P}_{2}\end{array}$ & rounded & $?$ \\
\hline
\end{tabular}

Note: Data for $C$. amamiaurea, $C$. unzenalba, and $C$. seiryusetea are based only on the respective holotype specimens.

Abbreviations: Fe, femur; $\mathrm{P}_{2}$, middle leg; $\mathrm{Ta}_{3}$, tarsomere 3; $\mathrm{Ti}$, tibia.

zanuvea Sasa and Suzuki, 2001 undoubtedly belongs to the genus Rheopelopia because of the features of the male hypopygium: the gonostylus gradually tapers towards its apex and the median volsella is quadrate, without any dorsolateral process (see Sasa and Suzuki 2001b). Therefore, this species is not treated in this study.

I have examined many specimens raised from immature stages, as well as type material of the new taxa described by Dr M. Sasa and now deposited in NSMT. As a result, some nominal specific taxa were revealed to be synonymous. Conchapelopia japonica is a senior synonym of C. multifascia (Tokunaga, 1937), C. quatuormaculata Fittkau, 1957, C. togasiroia Sasa and Okazawa, 1992, and C. familemea Sasa, 1996; and C. okisimilis, C. shikotuensis, and C. unzenalba are respectively senior synonyms of $C$. jintualba Sasa, 1990, $C$. ginzanvewea Sasa and Suzuki, 2001, and C. tusimugehea Sasa and Suzuki, 1999. Consequently, eight Japanese species, $C$. japonica, C. okisimilis, C. shikotuensis, C. togamaculosa, C. togapallida, C. amamiaurea, $C$. unzenalba, and $C$. seiryusetea are recognized as valid in this genus, although I have not seen specimens referable to the latter three species besides their respective holotypes. As mentioned above, the status of $C$. esakiana remains unclear.

For comparison, meristic data of major characters, measurements, and ratios of the eight Japanese species are summarized in Table 1. These species are easily distinguished by the following key. 


\section{Key to species of Conchapelopia from Japan}

\section{Male}

1. Hypopygium with median volsella rounded at basolateral corner .2

- Hypopygium with median volsella projecting triangularly or digitately at basolateral corner ....................................................................

2. Middle leg with tarsal brush C. seiryusetea

- Middle leg without tarsal brush C. togapallida

3. Median volsella with basolateral digitiform appendage 4

- Median volsella without basolateral digitiform appendage ........................5

4. Median volsella thickset; all legs without distinct dark rings C. japonica

- Median volsella slender; all legs with dark rings on femora and tibiae

Middle leg without tarsal brush C. shikotuensis

- Middle leg with tarsal brush C. okisimilis

6. All legs with dark rings on femora and tibiae; wing with dark bands

C. amamiaurea

- All legs without distinct dark rings; wing with or without dark bands...........7

7. Wing with dark bands C. togamaculosa

- Wing without dark bands .... C. unzenalba

Pupa (Pupae of C. amamiaurea, C. unzenalba, and C. seiryusetea are unknown)

1. Abdominal segment VIII with posterolateral spines $8-20 \mu \mathrm{m}$ long ................ 2

- Abdominal segment VIII with posterolateral spines $2-3 \mu \mathrm{m}$ long $\ldots \ldots \ldots \ldots \ldots \ldots \ldots . . .3$

2. Posterolateral spines of abdominal segment VIII $8-13 \mu \mathrm{m}$ long; abdominal segment VII with 4 pairs of lateral taeniae; corona occupying about apical half of thoracic horn C. okisimilis

- Posterolateral spines $13-20 \mu \mathrm{m}$ long on abdominal segment VIII; abdominal segment VII with 3 pairs of lateral taeniae; corona occupying about apical 0.30 of thoracic horn C. togapallida

3. Thoracic horn about 3.0 times as long as broad; plastron plate small, ratio of its maximum diameter to thoracic horn length $0.13-0.24 ; \mathrm{L}_{1}$-seta on abdominal segment IV about 0.30 times as long as segment IV .................. togamaculosa

- Thoracic horn about 2.0 times as long as broad; plastron plate large, ratio of its maximum diameter to thoracic horn length $0.35-0.68$; $\mathrm{L}_{1}$-seta on abdominal segment IV at most 0.20 times as long as segment IV

4. Respiratory atrium of thoracic horn apically distinct and T-shaped ....C. japonica

- Respiratory atrium of thoracic horn apically infuscate and amoeboid C. shikotuensis

Conchapelopia japonica (Tokunaga, 1937)

[Japanese name: Yamato-hime-yusurika]

(Figs 1-13, Table 2)

Pentaneura japonica Tokunaga, 1937a: 50; 1937b: 94.

Pentaneura melanops: Tokunaga 1937a: 51; 1937b: 94. [Not Pentaneura melanops Meigen, 1818] 
Pentaneura multifascia Tokunaga, 1937a: 54; 1937b: 99. Syn. nov. Conchapelopia quatuormaculata Fittkau, 1957: 320; 1962: 233. Syn. nov. Conchapelopia togasiroia Sasa and Okazawa, 1992: 210. Syn. nov. Conchapelopia sp., "togabimacula": Sasa and Okazawa 1992: 210. Conchapelopia japonica: Sasa and Kikuchi 1995: 84. Conchapelopia familemea Sasa, 1996: 61. Syn. nov. Conchapelopia multifascia: Sasa 1996: 62.

Material examined. Holotype of Conchapelopia togasiroia: o (NSMT-I-Dip 4751), labeled "No. A188: 17", tributary of Toga River in Toga Village, Toyama Prefecture, 11 September 1990. Holotype of Conchapelopia familemea: ot (NSMT-I-Dip 4939), labeled "No. A254: 85", Rokusen Lake in Toyama City Family Park, Toyama City, 24 August 1993. Non-types: 10 (NSMT-I-Dip), labeled "No. 188: 15, Conchapelopia sp., togabimacula", tributary of Toga River in Toga Village, Toyama Prefecture, 11 September 1990; $10^{\star}$ with its pupal and larval exuviae (SUM-IC-T 0046), small stream in Udo Hills, Shizuoka City, Shizuoka Prefecture, 30 March 1984 (adult emerged on 6 April 1984); 10 with its pupal and larval exuviae (SUM-IC$\mathrm{T}$ 0047), same locality, 24 October 1997 (adult emerged on 30 October 1997); $29 \%$ with their pupal exuviae (SUM-IC-T 0048, 0049), same locality, 10 April 1998 (adults emerged on 12 April and 11 May 1998); $10^{\hat{*}}$ with its pupal exuviae (SUM-IC-T 0050), same locality, 9 April 2000 (adult emerged on 27 April 2000); $500,39 q$, with all their pupal and larval exuviae (SUM-IC-T 0051-0058), same locality, 19 October 2000 (adults emerged on 21-29 October 2000); 1 \% with its pupal and larval exuviae (SUMIC-T 0059), same locality, 13 May 2001 (adult emerged on 22 May 2001); 1 ㅇ with its pupal exuviae (SUM-IC-T 0060), small stream in Ashikubo, Shizuoka City, 19 February 1988 (adult emerged on 25 February 1988); $1 \delta^{\wedge}$ (SUM-IC-T0061), same locality, 2 April 1988; $20^{\circ}$ with their pupal exuviae (SUM-IC-T 0062, 0063), Nagasawa River in Udo Hills, Shizuoka City, 30 November 1998 (adults emerged on 3 and 4 December 1998); 4 of with 1 of their pupal exuviae (SUM-IC-T 0064-0067), same locality, 13 May 2001 (adults emerged on 18-25 May 2001); 10 with its pupal and larval exuviae (SUM-IC-T 0068), Mariko River in Shizuoka City, 31 March 1982 (adult emerged on 15 April 1982); 200 , 19 with all their pupal exuviae and 2 of their larval exuviae (SUM-IC-T 0069-0071), Kadoya River in Shizuoka City, 4 May 1998 (adults emerged on 10-13 May 1998); 10 with its pupal exuviae (SUM-IC-T 0072), stream in Shishihara, Shimizu, Shizuoka City, 10 May 1998 (adult emerged on 15 May 1998); 2 के with 1 male's pupal and larval exuviae (SUM-IC-T 0073, 0074), small stream in Fujimi Town, Nagano Prefecture, 23 August 1998 (adults emerged on 26 and 27 August 1998); 10 with its pupal exuviae (SUM-IC-T 0075), small stream in Ichikai Town, Tochigi Prefecture, 15 August 1989 (adult emerged on 1 September 1989); 10 with its pupal and larval exuviae, (SUM-IC-T 0076), same locality, 4 May 1999 (adult emerged on 25 May 1999); 10 and 1 pupa, with the male's pupal exuviae (SUM-IC-T 0077, 0078), Asami River, Hirono Town, Fukushima Prefecture, 19 August 1999

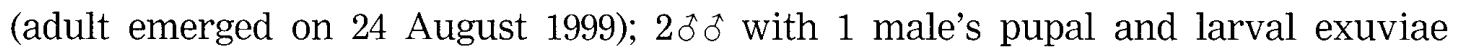
(SUM-IC-T 0079, 0080), small stream in Yaguki, Iwaki City, Fukushima Prefecture, 15 August 2001 (adults emerged on 20 and 22 August 2001).

Description. Male $(\mathrm{n}=26$, unless otherwise stated). Body length $3.2-4.6 \mathrm{~mm}$.

Coloration: Body predominantly pale yellow, with or without dark markings. Thorax with $0-4$ pairs of dark spots along pale scutal vittae (Fig. 1a-e). Abdominal 
tergites II-VI anteriorly darkened, tergites VII-IX extensively darkened, but these markings occasionally weak or absent on some tergites. Thorax entirely darkened on scutal vittae, anepisternum II, preepisternum, and postnotum in some specimens (Fig. 1f). Wings without any markings. Legs entirely pale yellow, or at most
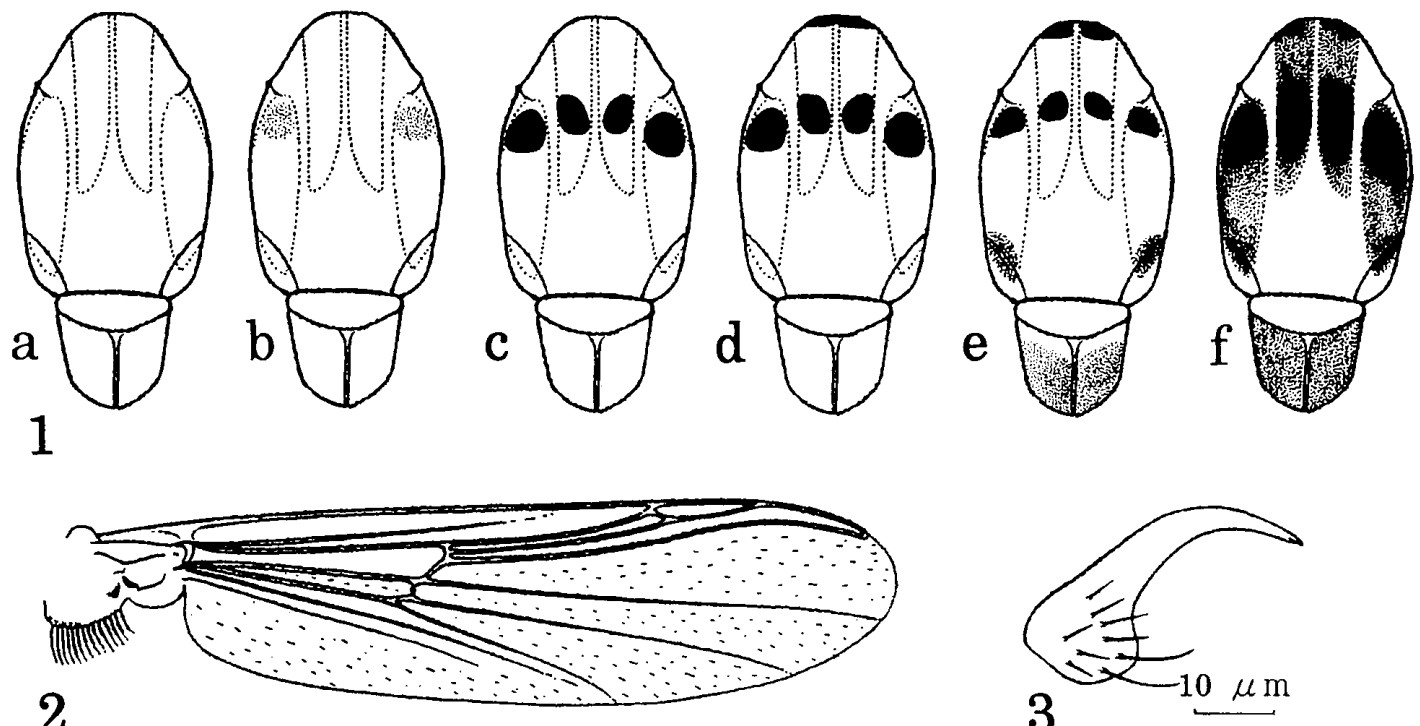

2

$1000 \mu \mathrm{m}$
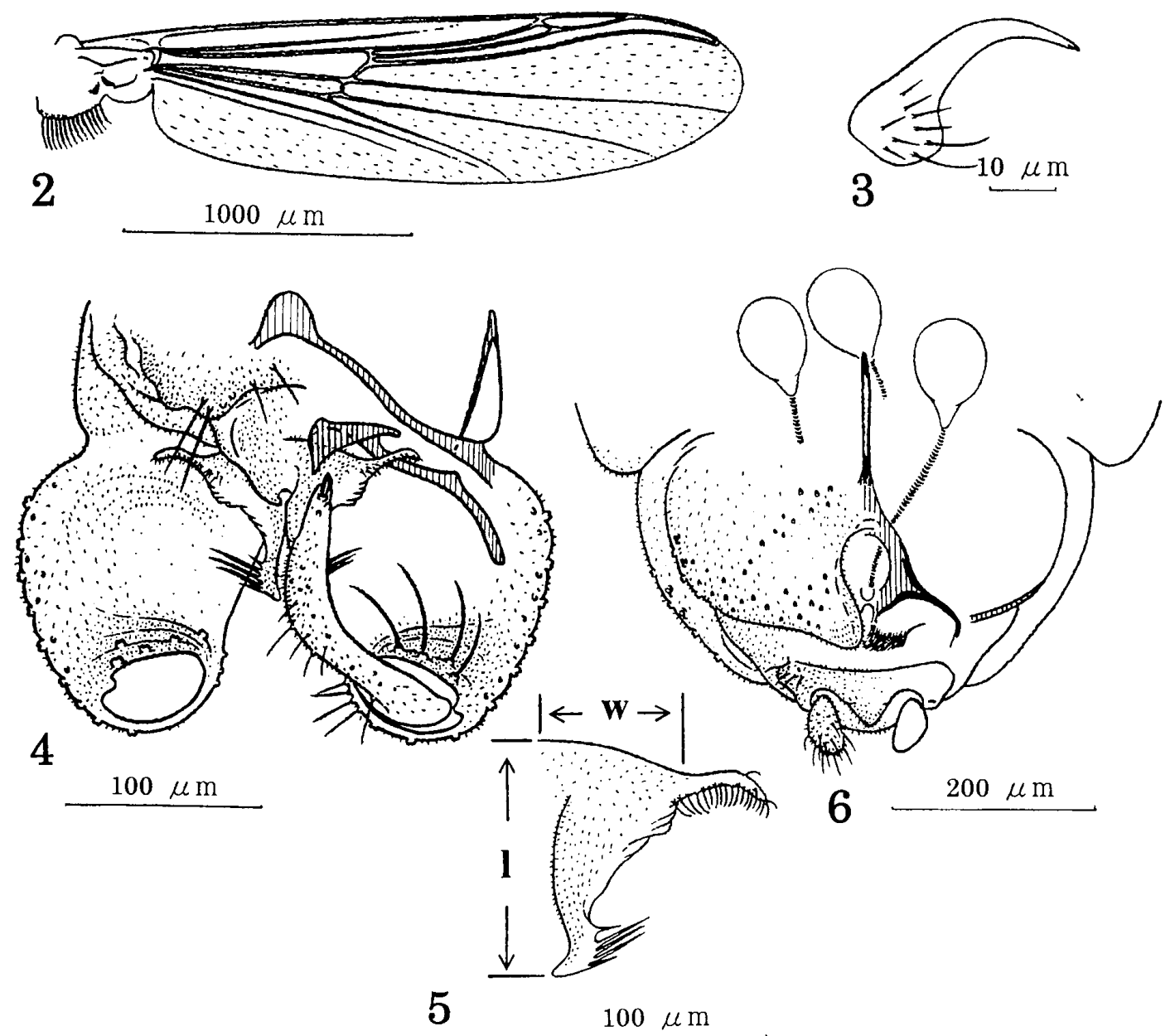

Figs 1-6. Conchapelopia japonica (Tokunaga, 1937), adult males, SUM-IC-T 0071 (1c, 2-5), 0073 (1a), 0075 (1b), 0079 (1d), 0046 (1e), 0061 (1f), and adult female, SUM-IC-T 0057 (6). 1a-f, Thorax, showing variations in marking pattern, dorsal view; 2 , wing; 3 , tarsal claw on middle leg, lateral view; 4, hypopygium, dorsal view; 5 , median volsella, dorsal view, showing measurements; 6 , genitalia, ventral view. Abbreviations: 1, length; w, width. 
brownish on apex of femur, both ends of tibia, and on tarsomeres 4-5.

Head: Temporals 14-24, uniserial, partly bi- or triserial. Antenna with apical seta $43-68 \mu \mathrm{m}$ long; antennal ratio 1.7-2.0. Clypeus rounded, with 13-36 setae. Lengths of palpomeres 1-5 (in $\mu \mathrm{m}, \mathrm{n}=23$ ) 50-90 (71), 85-125 (102), 150-225 (182), 175-250 (205), and 263-410 (312), respectively.

Thorax: Antepronotum with 4-20 lateral setae on each lobe. Scutal tubercle $10-23 \mu \mathrm{m}$ high. Acrostichals 42-80, biserial between median scutal vittae; dorsocentrals 16-36, medially uniserial, anteriorly and posteriorly bi- or triserial; humerals 5-19; prealars 13-26, uniserial, partly multiserial; supraalars 1-3, usually 2; no preepisternals. Scutellum with 21-42 setae. Wings (Fig. 2) 2.1-3.6 mm long; venarum ratio $0.86-0.94$; squama with $23-62$ setae. All legs with long tibial spurs each bearing 7-13 lateral teeth; ratio of inner spur length to outer spur length 1.0-1.4 in middle leg, 1.5-1.7 in hind leg; hind leg with tibial comb of 5-7, usually 6 , spines. Tarsal beard moderately long; bristle ratio 4.4-8.2 in foreleg, 5.4-8.2 in middle leg, 5.7-7.5 in hind leg; middle leg without tarsal brush. Tarsal claws pointed apically in fore- and hind legs, trifid in middle leg (Fig. 3), and each claw with several short spines basoventrally; pulvilli absent. Lengths and ratios of leg segments as shown in Table 2.

Hypopygium (Fig. 4): Tergite IX with 9-19 setae, many of them concentrated posterolaterally; lateral tubercle indistinct. Gonocoxite $150-200 \mu \mathrm{m}$ long, with 4-7, usually 5, large preapical setae. Median volsella (Fig. 5) somewhat thickset, 80-108 $\mu \mathrm{m}$ long, 1.6-2.0 times as long as wide, with digitiform appendage basolaterally and 3-7 gradually tapered processes on about apical quarter; ventral lobe absent.

Female $(\mathrm{n}=8$, unless otherwise stated). Body length $2.2-3.6 \mathrm{~mm}$.

Coloration: Similar to male, but entirely pale yellow on abdomen.

Head: Temporals 17-27 in number. Antenna with apical seta 58-83 $\mu \mathrm{m}$ long; terminal flagellomere almost as long as or slightly longer than preceding 3 flagellomeres together; antennal ratio 0.26-0.31. Clypeus with 18-34 setae. Lengths of palpomeres 1-5 (in $\mu \mathrm{m}, \mathrm{n}=6$ ) 50-88 (62), 95-125 (105), 150-200 (180), 180-230 (207), and 275-335 (309), respectively.

Thorax: Antepronotum with 5-9 lateral setae on each lobe. Scutal tubercle 10$23 \mu \mathrm{m}$ high. Acrostichals 60-89 in number, dorsocentrals 25-37, humerals 14-22, prealars 19-30, supraalars 1-3 (usually 2), no preepisternals. Scutellum with 30-48 setae. Wings $2.3-2.8 \mathrm{~mm}$ long; venarum ratio $0.86-0.91$; squama with $26-47$ setae. All legs with tibial spurs each bearing 8-11 lateral teeth; ratio of inner spur length to outer spur length 1.1-1.3 in middle leg, 1.4-1.7 in hind leg. All tarsal claws pointed apically, each with short basoventral spines; pulvilli absent. Lengths and ratios of leg segments as shown in Table 2.

Genitalia (Fig. 6): Gonotergite IX without setae. Labium with apical microtrichia. Seminal capsule pale, oval, $83-103 \mu \mathrm{m}$ long and $63-80 \mu \mathrm{m}$ wide. Segment $\mathrm{X}$ with $7-16$ setae on each side.

Pupa ( $\mathrm{n}=29$, unless otherwise stated). Body length 4.0-6.2 mm.

Coloration: Exuviae pale brown with dark scar and apophyses on abdomen.

Cephalothorax: Thoracic horn (Fig. 7a, b) 260-385 $\mu \mathrm{m}$ long and 1.9-2.4 times as long as broad. Plastron plate oval and large; ratio of its maximum diameter to length of thoracic horn $0.35-0.68$. Corona occupying apical $0.46-0.71$ of thoracic horn; ratio of maximum diameter of plastron plate to length of corona $0.74-0.98$. Respiratory atrium T-shaped apically in many specimens. 
Table 2. Lengths (in $\mu \mathrm{m}$ ) and ratios of leg segments in 26 males and eight females of Conchapelopia japonica (Tokunaga, 1937).

\begin{tabular}{|c|c|c|c|c|c|}
\hline & Coxa & Trochanter & Femur & Tibia & Tarsomere 1 \\
\hline \multicolumn{6}{|l|}{ Male } \\
\hline Foreleg & $\begin{array}{c}200-310 \\
(250)\end{array}$ & $\begin{array}{c}140-230 \\
(190)\end{array}$ & $\begin{array}{c}860-1240 \\
(1020)\end{array}$ & $\begin{array}{c}1090-1540 \\
(1250)\end{array}$ & $\begin{array}{c}870-1230 \\
(1020)\end{array}$ \\
\hline Middle leg & $\begin{array}{c}340-500 \\
(410)\end{array}$ & $\begin{array}{c}110-150 \\
(130)\end{array}$ & $\begin{array}{c}960-1360 \\
(1090)\end{array}$ & $\begin{array}{c}970-1330 \\
(1080)\end{array}$ & $\begin{array}{c}570-730 \\
(630)\end{array}$ \\
\hline Hind leg & $\begin{array}{c}290-420 \\
(340)\end{array}$ & $\begin{array}{c}100-150 \\
(120)\end{array}$ & $\begin{array}{c}820-1290 \\
(980)\end{array}$ & $\begin{array}{c}1210-1800 \\
(1400)\end{array}$ & $\begin{array}{c}850-1230 \\
(1000)\end{array}$ \\
\hline \multicolumn{6}{|l|}{ Female } \\
\hline Foreleg & $\begin{array}{c}200-280 \\
(250)\end{array}$ & $\begin{array}{c}160-220 \\
(190)\end{array}$ & $\begin{array}{c}920-1230 \\
(1010)\end{array}$ & $\begin{array}{c}1110-1540 \\
(1290)\end{array}$ & $\begin{array}{c}840-1210 \\
(1000)\end{array}$ \\
\hline Middle leg & $\begin{array}{c}350-480 \\
(420)\end{array}$ & $\begin{array}{c}120-160 \\
(140)\end{array}$ & $\begin{array}{c}930-1400 \\
(1120)\end{array}$ & $\begin{array}{c}1000-1460 \\
(1180)\end{array}$ & $\begin{array}{c}600-840 \\
(690)\end{array}$ \\
\hline \multirow[t]{2}{*}{ Hind leg } & $\begin{array}{c}290-450 \\
(360)\end{array}$ & $\begin{array}{c}110-160 \\
(130)\end{array}$ & $\begin{array}{c}800-1210 \\
(980)\end{array}$ & $\begin{array}{c}1270-1870 \\
(1460)\end{array}$ & $\begin{array}{c}760-1190 \\
(940)\end{array}$ \\
\hline & Tarsomere 2 & Tarsomere 3 & Tarsomere 4 & Tarsomere 5 & Leg ratio \\
\hline \multicolumn{6}{|l|}{ Male } \\
\hline Foreleg & $\begin{array}{c}450-650 \\
(530)\end{array}$ & $\begin{array}{c}310-480 \\
(380)\end{array}$ & $\begin{array}{c}220-340 \\
(270)\end{array}$ & $\begin{array}{c}120-180 \\
(150)\end{array}$ & $0.75-0.87$ \\
\hline Middle leg & $\begin{array}{c}250-400 \\
(310)\end{array}$ & $\begin{array}{c}190-300 \\
(230)\end{array}$ & $\begin{array}{c}160-250 \\
(190)\end{array}$ & $\begin{array}{c}100-130 \\
(110)\end{array}$ & $0.55-0.63$ \\
\hline Hind leg & $\begin{array}{c}430-700 \\
(550)\end{array}$ & $\begin{array}{c}340-530 \\
(420)\end{array}$ & $\begin{array}{c}220-360 \\
(270)\end{array}$ & $\begin{array}{c}120-180 \\
(150)\end{array}$ & $0.68-0.78$ \\
\hline \multicolumn{6}{|l|}{ Female } \\
\hline Foreleg & $\begin{array}{c}450-680 \\
(530)\end{array}$ & $\begin{array}{c}290-490 \\
(370)\end{array}$ & $\begin{array}{c}210-340 \\
(250)\end{array}$ & $\begin{array}{c}120-180 \\
(140)\end{array}$ & $0.76-0.81$ \\
\hline Middle leg & $\begin{array}{c}290-410 \\
(340)\end{array}$ & $\begin{array}{c}210-330 \\
(250)\end{array}$ & $\begin{array}{c}160-260 \\
(190)\end{array}$ & $\begin{array}{c}100-140 \\
(120)\end{array}$ & $0.56-0.62$ \\
\hline Hind leg & $\begin{array}{c}430-710 \\
(540)\end{array}$ & $\begin{array}{c}330-550 \\
(420)\end{array}$ & $\begin{array}{c}220-350 \\
(270)\end{array}$ & $\begin{array}{c}130-170 \\
(140)\end{array}$ & $0.60-0.67$ \\
\hline
\end{tabular}

Lengths are given as ranges and means (in parentheses).

Abdomen: Shagreen (Fig. 8) mainly consisting of multifid spinules on tergites I-VIII, but of simple spinules on tergite IX. Segments I-VI each with 2 pairs of flattened L-setae; $\mathrm{L}_{1}$-seta on segment IV $70-88 \mu \mathrm{m}$ long and $0.15-0.19$ times as long as segment length. Segment VII with 4 pairs of lateral taeniae on about posterior 0.40 , and segment VIII with 5 pairs of lateral taeniae on about posterior half (Fig. 9). Anal lobe $320-500 \mu \mathrm{m}$ long and 1.8-2.2 times as long as broad. Male genital sac $0.65-0.72$ times as long as anal lobe.

Fourth instar larva $(\mathrm{n}=17$, unless otherwise stated). Body length $4.5-7.0 \mathrm{~mm}$.

Coloration: Head and claws of posterior parapod yellow and body yellowishwhite in life.

Head (Fig. 10): Length 700-780 $\mu \mathrm{m}$; cephalic index 0.57-0.60. Dorsal cephalic seta $S_{8}$ lateral to dorsal sensory pore and close to $S_{7}$; ventral cephalic seta $S_{10}$ pos- 

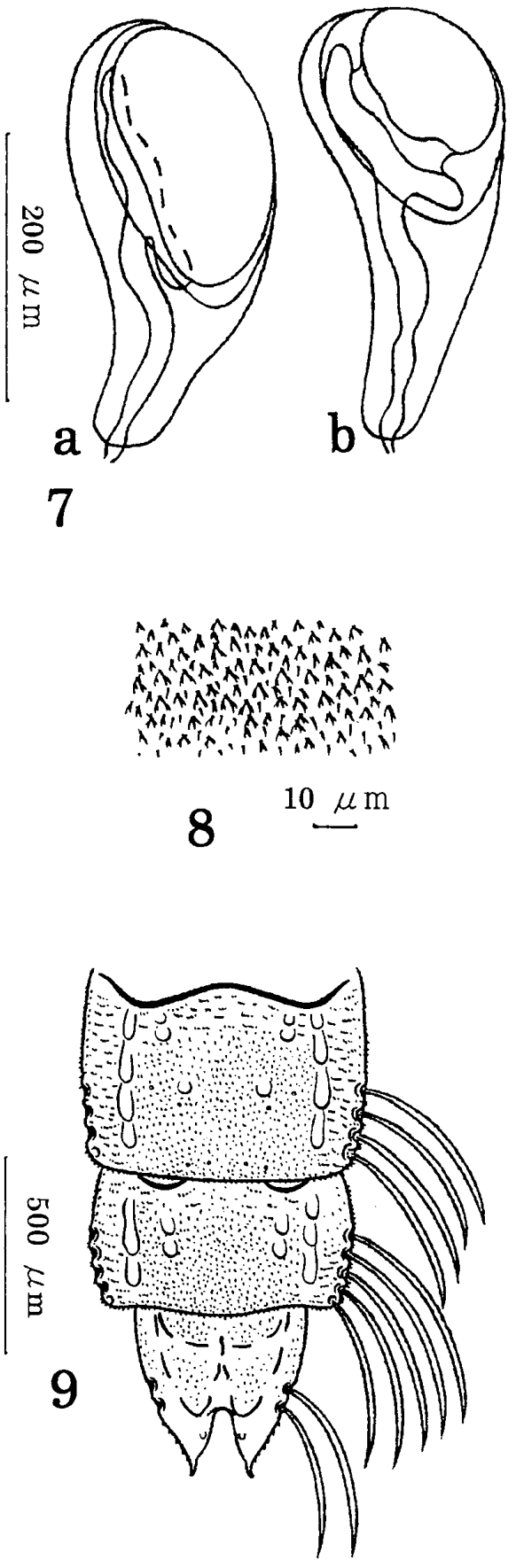
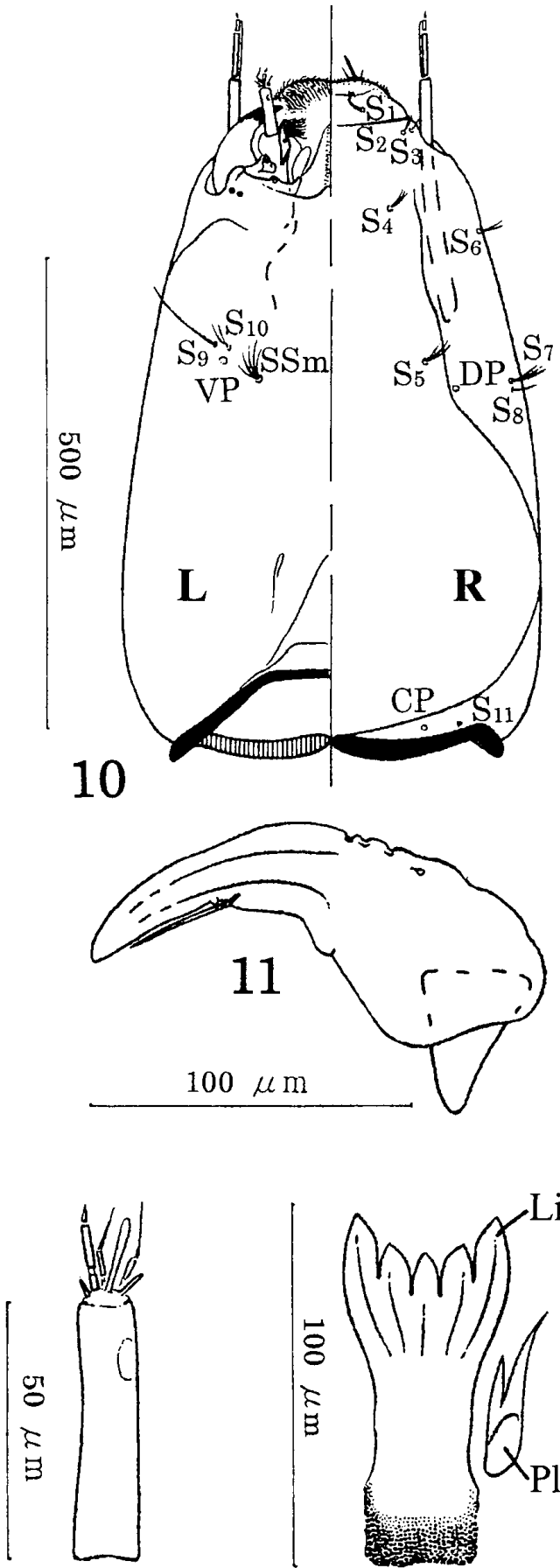

12

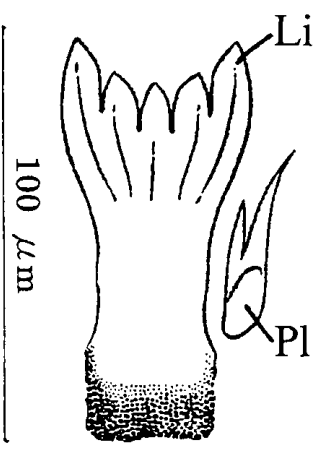

13

Figs 7-13. Conchapelopia japonica (Tokunaga, 1937), pupal exuviae, SUM-IC-T 0071 (7a), 0078 (7b, 8, 9), and larval exuviae, SUM-IC-T 0047 (10), 0053 (11-13). 7a, b, Thoracic horn, showing morphological variation; 8, shagreen on posteromedial part of abdominal tergite IV; 9 , abdominal segments VII-IX, dorsal view (only right lateral setae shown); 10, head with chaetotaxy, dorsal view (R) and ventral view (L); 11, mandible; 12, maxillary palp; 13, ligula and paraligula. Abbreviations: CP, coronal sensory pore; DP, dorsal sensory pore; Li, ligula; Pl, paraligula; $\mathrm{S}_{1-11}$, cephalic setae 1-11; SSm, seta submenti; VP, ventral sensory pore. 
teromedial to $\mathrm{S}_{9}$ and anteromedial to ventral sensory pore. Lengths of antennal segments I-IV (in $\mu \mathrm{m}, \mathrm{n}=12$ ) 250-320 (274), 48-55 (50), 6-7 (6), and 5-6 (5), respectively; antennal ratio 4.2-4.9. Antennal segment I 8.8-10.8 times as long as its basal width, with ring organ positioned $0.27-0.32$ of way from apex; blade $53-61 \mu \mathrm{m}$ long, $3.9-5.1$ times as long as its basal ring, reaching to apex of segment III; accessory blade $45-60 \mu \mathrm{m}$ long. Antennal segment II 8.0-10.6 times as long as its basal width; style $7-10 \mu \mathrm{m}$ long and reaching to middle of segment IV; Lauterborn organ $3-5 \mu \mathrm{m}$ long. Mandible (Fig. 11) 128-158 $\mu \mathrm{m}$ long. Basal segment of maxillary palp (Fig. 12) $45-55 \mu \mathrm{m}$ long, 3.2-3.7 times of its basal width, with ring organ positioned $0.18-0.24$ of way from apex. M-appendage with 7 or 8 rows of granules on pseudoradula. Ligula (Fig. 13) $88-105 \mu \mathrm{m}$ long and almost twice as long as its broadest width. Paraligula bifid and $40-48 \mu \mathrm{m}$ long; fork positioned $0.42-0.53$ of way from base. Pecten hypopharyngis with $17-22$ teeth on each side.

Body: Procercus 3.5 4.0 times as long as wide, with 7 anal setae. Four anal tubules each almost 5 times as long as wide, tapering to pointed apex.

Distribution. Japan (Fukushima, Tochigi, Shizuoka, Nagano, Toyama, and Kyoto Prefectures).

Remarks. Tokunaga (1937a) described Conchapelopia japonica on the basis of the female holotype, which was characterized by the presence of four pairs of dark spots on the scutal vittae and the entirely white abdomen. The holotype may be still extant in the collection of the Kyushu University Museum. But even so, the condition may be too poor to make necessary observations because of the longterm alcoholic storage. During this study, I examined 26 male specimens referred to $C$. japonica. They showed great variation in the scutal marking pattern as follows: three specimens (11.5\%) have no conspicuous markings (A-morph, Fig. 1a); three specimens $(11.5 \%$ ) have one pair of dark spots (B-morph, Fig. 1b); thirteen specimens $(50.0 \%)$ have two pairs of spots (C-morph, Fig. 1c); three specimens $(11.5 \%)$ have three pairs of spots (D-morph, Fig. 1d); two specimens $(7.7 \%)$ have four pairs of spots (E-morph, Fig. 1e); and two specimens $(7.7 \%)$ are largely pigmented on the scutal vittae (F-morph, Fig. 1f). The abdominal marking pattern also varies among specimens. Dark markings occur at least on abdominal tergites III-VII in all the D-, E-, and F-morph specimens, $69.2 \%$ of the C-morph specimens, and $66.7 \%$ of the B-morph specimens. The two F-morph specimens are darkly pigmented on tergites II, VIII, and IX, too. The A-morph specimens do not have any markings on the abdomen besides on tergite VII. This species shows a tendency to be pigmented on the abdomen as well as the thorax. Even in the dark morphs, however, the wings and legs are not distinctly pigmented, although one of the two Fmorph specimens has its legs pigmented slightly on the apex of the femur, both ends of the tibia, and on tarsomeres 4-5. Kobayashi and Hayashi (2001) also reported variation in the coloration of $C$. japonica (under the name Conchapelopia sp. B), noting (p. 42) "The scutal marking patterns of this species, however, varied greatly among individuals, with a continuous pattern in which darker individuals seemed to appear in relatively cold seasons." Indeed, the present F-morph specimens were collected in early spring.

The observed variation led me to question the validity of several previously described specific taxa, viz., Conchapelopia multifascia, C. quatuormaculata, $C$. togasiroia, and C. familemea. Conchapelopia multifascia was described on the basis of the male holotype, which has three largely darkened vittae on the scutum and 
some dark bands on the abdomen (Tokunaga 1937a). The holotype may be still extant in the Kyushu University Museum as an alcoholic specimen, but even so, its condition may be too poor to make necessary observations. Nevertheless, there is little doubt that the holotype corresponds to the F-morph of $C$. japonica. Consequently, C. multifascia is synonymized with $C$. japonica.

Fittkau (1957) considered that Pentaneura melanops reported by Tokunaga (1937a) from Japan represented a species distinct from the true P. melanops mainly because of the morphological differences between their male hypopygia. He proposed a new name, Conchapelopia quatuormaculata, for P. melanops of Tokunaga (1937a). The species separation by Fittkau is reasonable, because Tokunaga (1937a, fig. 89) illustrated the hypopygial median volsella of his specimen referred to $P$. melanops as having a broad and short basolateral digitiform appendage and an apically sclerotized projection at the base. Judging from the general shape, however, the sclerotized projection seems to correspond to an apical part of the opposite gonostylus with a megaseta; therefore, it can be said that Tokunaga (1937a) illustrated the hypopygial median volsella in an obligue view. Tokunaga (1937a) recognized Pentaneura melanops as having two pairs of dark spots on the scutal vittae and some dark bands on the male abdomen. It is obvious that Tokunaga's (1937a) $P$. melanops corresponds to the C-morph of $C$. japonica recognized in this study. Consequently, Fittkau's (1957) taxon C. quatuormaculata is synonymized with $C$. japonica.

Sasa and Okazawa (1992) described Conchapelopia togasiroia on the basis of two male specimens, noting (p. 210) "These specimens are also typical members of Conchapelopia, and are especially characteristic in that body is almost entirely pale and without dark marks, and the basal lobes of gonocoxite has a group of long apical setae, a long basolateral arm, and without lateral processes between them." Furthermore, Sasa (1996) described Conchapelopia familemea on the basis of a single male specimen, and recognized this species as having a largely white body except for five scutal and two postnotal dark areas partially speckled with pale bubbles. Reexamination of the holotypes of both of these nominal species showed that the median volsellae of $C$. togasiroia and $C$. familemea are somewhat thickset and armed with a digitiform appendage basolaterally and gradually tapered processes apically. These features correspond to those of $C$. japonica (Fig. 5). In addition, the holotype of C. familemea has eight dark markings on the scutum, rather than five, although the four markings on the median vittae are very faint. The pale bubbles in the thoracic dark areas may represent intraspecific variation. Conchapelopia togasiroia and $C$. familemea are junior synonyms of $C$. japonica, and referred to the A-morph and E-morph, respectively, of the latter species.

Sasa and Okazawa (1992) provisionally recognized an informal taxon Conchapelopia sp., "togabimacula", because the specimens referred to it differed from other known species in coloration, with an almost entirely pale body except for a pair of brown spots on the scutum. I have confirmed that the specimens, which are now in the collection of NSMT, are identical with the A-morph of C. japonica.

Conchapelopia japonica is morphologically very similar to European $C$. melanops, especially in the structure of the male hypopygium. However, it is separable from $C$. melanops by the presence of a corona on the pupal thoracic horn. According to Fittkau (1962), Langton (1984), and Fittkau and Murray (1986), the pupa of C. melanops has no corona on the thoracic horn. Conchapelopia melanops has 
been considered to be widely distributed in Europe, Asia, and North America (Malloch 1915; Ashe and Cranston 1991); however, Roback (1966: 124) noted "To date, however, I have seen no New World material which is conspecific with the European specimens." Later, Roback (1971) referred some North American specimens, earlier identified with $C$. melanops, to $C$. dusena Roback, 1971 or C. rurika (Roback, 1957). Wang (1994) reported $C$. melanops on the basis of a larva from Hunan Province, China, but this record needs to be verified.

Conchapelopia okisimilis Sasa, 1990

[Japanese name: Mumon-torafu-yusurika]

(Figs 14 25, Table 3)

Conchapelopia okisimilis Sasa, 1990a: 137.

Conchapelopia jintualba Sasa, 1990b: 51. Syn. nov.

Conchapelopia sp. B, "seiryuteua": Sasa et al. 1998: 127.

Material examined. Holotype of Conchapelopia okisimilis: of (NSMT-I-Dip 4681), labeled "No. A174: 91", small stream in Giho, Naha City, Okinawa Island, Okinawa Prefecture, 26 November 1988 (adult emerged on 3 February 1989). Holotype of Conchapelopia jintualba: ô (NSMT-I-Dip 4823), labeled “No. 214: 4”, Jintsu River in Monjuji, Toyama City, 26 February 1990. Non-types: 1ơ (NSMT-I-Dip), labeled "No. 359: 05 (\#9-1), Conchapelopia sp. B, seiryuteua", Shimanto River in Hiyoshi Village, Ehime Prefecture, 26 April 1998; 1 \% (SUM-IC-T 0081), Ihara River in Shizuoka City, Shizuoka Prefecture, 25 September 1990; $40 \delta, 299$, with all their pupal exuviae (SUM-IC-T 0082-0087), small stream in Udo Hills, Shizuoka City, 15 April 1993 (adults emerged on 18-25 April 1993); 10 with its pupal exuviae (SUM-ICT 0088), same locality, 7 July 2000 (adult emerged on 15 July 2000); $2 \delta 8,19$, with all their pupal exuviae (SUM-IC-T 0089-0091), same locality, 19 October 2000 (adults emerged on 26-29 October 2000); 4 \% 9,1 larva, with the females' pupal and larval exuviae (SUM-IC-T 0092-0096), same locality, 10 May 2001 (adults emerged on 15-19 May 2001); 1 \% with its pupal and larval exuviae (SUM-IC-T 0097), same locality, 30

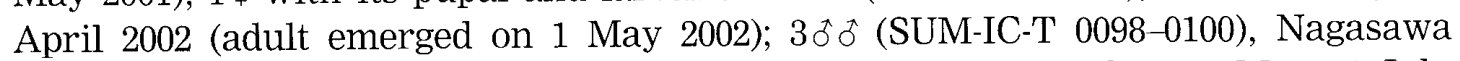
River in Udo Hills, Shizuoka City, 13 May 2001 (adults emerged on 25 May-21 July 2001); $10^{\star}$ with its pupal exuviae (SUM-IC-T0101), small stream in Ashikubo, Shizuoka City, 15 February 1996 (adult emerged on 25 February 1996); 1 \% with its pupal exuviae (SUM-IC-T 0102), same locality, 10 January 1999 (adult emerged on 15 February 1999); 19 with its pupal exuviae (SUM-IC-T 0103), small stream in Ikawa, Shizuoka City, 15 September 1996 (adult emerged on 20 September 1996); $10^{\star}, 1$ larva (SUM-IC-T 0104, 0105), same locality, 4 May 1998; 19 with its pupal exuviae (SUMIC-T 0106), same locality, 29 August 2000 (adult emerged on 16 September 2000); 10 (SUM-IC-T 0107), Inase River in Shibakawa Town, Shizuoka Prefecture, 15 July 1991; $3 \delta^{\circ} \delta$, 1 , with all their pupal exuviae (SUM-IC-T 0108-0111), small stream in Miyagase, Kiyokawa Village, Kanagawa Prefecture, 19 August 1992 (adults emerged on 25-27 August 1992); 19 with its pupal exuviae (SUM-IC-T 0112), same locality, 8 June 1997 (adult emerged on 10 June 1997); 10 with its pupal and larval exuviae (SUM-IC-T 0113), same locality, 7 February 1998 (adult emerged on 20 March 1998); 10, 19, with their pupal exuviae (SUM-IC-T 0114, 0115), small stream in 
Yaguki, Iwaki City, Fukushima Prefecture, 2 January 2001 (adults emerged on 16 and 20 January 2001).

Description. Male $(\mathrm{n}=18$, unless otherwise stated). Body length $3.0-3.8 \mathrm{~mm}$.

Coloration: Body usually pale yellow except for broadly darkened abdominal tergite VII, but entirely pale yellow in some specimens. Wings without any markings. Legs pale yellow.

Head: Temporals 15-23, uniserial, partly bi- or triserial. Antenna with apical seta 48-68 $\mu \mathrm{m}$ long; antennal ratio 1.5-1.7. Clypeus rounded, with 14-20 setae. Lengths of palpomeres 1-5 (in $\mu \mathrm{m}, \mathrm{n}=16$ ) 53-80 (64), 75-100 (84), 150-190 (161), 175-220 (190), and 240-325 (285), respectively.

Thorax: Antepronotum with 6-11 lateral setae on each lobe. Scutal tubercle $10-15 \mu \mathrm{m}$ high. Acrostichals 44-57, biserial between median scutal vittae; dorsocentrals 14-28, medially uniserial, anteriorly and posteriorly bi- or triserial; humerals 6-15; prealars 12-21, uniserial, partly multiserial; 1 supraalar; no preepisternals. Scutellum with $21-30$ setae. Wings $1.9-2.7 \mathrm{~mm}$ long; venarum ratio $0.84-0.93$; squama with 18-28 setae. All legs with long tibial spurs each bearing 6-11 lateral teeth; ratio of inner spur length to outer spur length 1.0-1.3 in middle leg, 1.5-1.8 in hind leg; hind leg with tibial comb of $5-7$, usually 6 , spines. Tarsi with moderately long beards; bristle ratio 5.0-7.6 in foreleg, 4.7-7.8 in middle leg, 5.1-7.6 in hind leg; tarsal brush absent. All tarsal claws sharply pointed apically, and each with 1 long and several short spines basoventrally; pulvilli absent. Lengths and ratios of leg segments as shown in Table 3.

Hypopygium (Fig. 14): Tergite IX with 13-24 setae, many of them concentrated posterolaterally; lateral tubercle indistinct. Gonocoxite $113-138 \mu \mathrm{m}$ long with $4-5$, usually 4, large preapical setae. Median volsella (Fig. 15) $68-83 \mu \mathrm{m}$ long, projecting triangularly at basolateral corner, with 6-9 curved and partially expanded dorsolateral processes on about basal 0.70 and 2-5 more or less straight processes on about apical 0.30; digitiform appendage and ventral lobe absent.

Female $(\mathrm{n}=15$, unless otherwise stated). Body length $2.2-3.1 \mathrm{~mm}$.

Coloration: Entirely pale yellow.

Head: Temporals 14-24 in number. Antenna with apical seta $48-70 \mu \mathrm{m}$ long; terminal flagellomere almost as long as preceding 3 flagellomeres together; antennal ratio $0.26-0.33$. Clypeus with $13-27$ setae. Lengths of palpomeres $1-5$ (in $\mu \mathrm{m}, \mathrm{n}=12$ ) 50-70 (62), 88-115 (97), 125-185 (172), 150-225 (196), and 225-345 (298), respectively.

Thorax: Antepronotum with 0-9 lateral setae on each lobe. Scutal tubercle 8-15 $\mu \mathrm{m}$ high. Acrostichals 39-71 in number, dorsocentrals 17-39, humerals 12-29, prealars 10-27, supraalars 1-2 (usually 1), no preepisternals. Scutellum with 21-41 setae. Wings $1.8-2.8 \mathrm{~mm}$ long; venarum ratio 0.83-0.93; squama with $13-36$ setae. All legs with tibial spurs each bearing 7-10 lateral teeth; ratio of inner spur length to outer spur length 1.0-1.3 in middle leg, 1.5-1.8 in hind leg. All tarsal claws pointed apically, each with 1 long and several short spines basoventrally; pulvilli absent. Lengths and ratios of leg segments as shown in Table 3.

Genitalia (Fig. 16): Gonotergite IX without setae. Labium with apical microtrichia. Seminal capsule pale, oval, $65-100 \mu \mathrm{m}$ long and $53-75 \mu \mathrm{m}$ wide. Segment $\mathrm{X}$ with 3-9 setae on each side.

Pupa ( $\mathrm{n}=27$, unless otherwise stated). Body length 3.7-5.0 mm.

Coloration: Exuviae pale yellow, with dark scar and apophyses on abdomen.

Cephalothorax: Thoracic horn (Fig. 17a-c) 240-300 $\mu \mathrm{m}$ long and 2.4-3.2 times as 
Table 3. Lengths (in $\mu \mathrm{m}$ ) and ratios of leg segments in 18 males and 15 females of Conchapelopia okisimilis Sasa, 1990.

\begin{tabular}{|c|c|c|c|c|c|}
\hline & Coxa & Trochanter & Femur & Tibia & Tarsomere 1 \\
\hline \multicolumn{6}{|l|}{ Male } \\
\hline Foreleg & $\begin{array}{c}190-240 \\
(210)\end{array}$ & $\begin{array}{c}150-200 \\
(170)\end{array}$ & $\begin{array}{c}840-1090 \\
(950)\end{array}$ & $\begin{array}{c}960-1280 \\
(1110)\end{array}$ & $\begin{array}{c}790-1090 \\
(920)\end{array}$ \\
\hline Middle leg & $\begin{array}{c}300-420 \\
(360)\end{array}$ & $\begin{array}{c}100-140 \\
(120)\end{array}$ & $\begin{array}{c}870-1110 \\
(990)\end{array}$ & $\begin{array}{c}810-1120 \\
(950)\end{array}$ & $\begin{array}{c}490-630 \\
(550)\end{array}$ \\
\hline Hind leg & $\begin{array}{c}280-340 \\
(310)\end{array}$ & $\begin{array}{c}100-120 \\
(110)\end{array}$ & $\begin{array}{c}790-1010 \\
(890)\end{array}$ & $\begin{array}{c}1030-1380 \\
(1220)\end{array}$ & $\begin{array}{c}730-1020 \\
(880)\end{array}$ \\
\hline \multicolumn{6}{|l|}{ Female } \\
\hline Foreleg & $\begin{array}{c}200-250 \\
(220)\end{array}$ & $\begin{array}{c}150-200 \\
(170)\end{array}$ & $\begin{array}{c}740-1130 \\
(930)\end{array}$ & $\begin{array}{c}960-1370 \\
(1130)\end{array}$ & $\begin{array}{c}710-1070 \\
(890)\end{array}$ \\
\hline Middle leg & $\begin{array}{c}300-450 \\
(380)\end{array}$ & $\begin{array}{c}100-130 \\
(120)\end{array}$ & $\begin{array}{c}830-1240 \\
(1020)\end{array}$ & $\begin{array}{c}840-1250 \\
(1030)\end{array}$ & $\begin{array}{c}480-710 \\
(580)\end{array}$ \\
\hline \multirow[t]{2}{*}{ Hind leg } & $\begin{array}{c}270-350 \\
(310)\end{array}$ & $\begin{array}{c}100-130 \\
(120)\end{array}$ & $\begin{array}{c}720-1090 \\
(900)\end{array}$ & $\begin{array}{c}1030-1580 \\
(1280)\end{array}$ & $\begin{array}{c}650-970 \\
(820)\end{array}$ \\
\hline & Tarsomere 2 & Tarsomere 3 & Tarsomere 4 & Tarsomere 5 & Leg ratio \\
\hline \multicolumn{6}{|l|}{ Male } \\
\hline Foreleg & $\begin{array}{c}420-550 \\
(470)\end{array}$ & $\begin{array}{c}300420 \\
(340)\end{array}$ & $\begin{array}{c}200-280 \\
(230)\end{array}$ & $\begin{array}{c}120-150 \\
(140)\end{array}$ & $0.76 \quad 0.87$ \\
\hline Middle leg & $\begin{array}{c}230-300 \\
(270)\end{array}$ & $\begin{array}{c}180-230 \\
(200)\end{array}$ & $\begin{array}{c}140-180 \\
(160)\end{array}$ & $\begin{array}{c}90-110 \\
(100)\end{array}$ & $0.55-0.61$ \\
\hline Hind leg & $\begin{array}{c}400-540 \\
(460)\end{array}$ & $\begin{array}{c}300-430 \\
(360)\end{array}$ & $\begin{array}{c}200-280 \\
(230)\end{array}$ & $\begin{array}{c}120-150 \\
(130)\end{array}$ & $0.66-0.75$ \\
\hline \multicolumn{6}{|l|}{ Female } \\
\hline Foreleg & $\begin{array}{c}340-550 \\
(460)\end{array}$ & $\begin{array}{c}240-380 \\
(320)\end{array}$ & $\begin{array}{c}170-260 \\
(220)\end{array}$ & $\begin{array}{c}110-150 \\
(130)\end{array}$ & $0.74-0.86$ \\
\hline Middle leg & $\begin{array}{c}230-330 \\
(280)\end{array}$ & $\begin{array}{c}170-240 \\
(210)\end{array}$ & $\begin{array}{c}120-180 \\
(150)\end{array}$ & $\begin{array}{c}90-120 \\
(100)\end{array}$ & $0.54-0.60$ \\
\hline Hind leg & $\begin{array}{c}360-550 \\
(450)\end{array}$ & $\begin{array}{c}280-410 \\
(350)\end{array}$ & $\begin{array}{c}180-260 \\
(220)\end{array}$ & $\begin{array}{c}110-150 \\
(130)\end{array}$ & $0.61-0.68$ \\
\hline
\end{tabular}

Lengths are given as ranges and means (in parentheses).

long as broad. Plastron plate oval, 0.9-1.4 times as long as wide, occupying about apical 0.30 of thoracic horn; ratio of its maximum diameter to length of thoracic horn $0.24-0.39$. Corona large, occupying apical $0.43-0.59$ of thoracic horn; ratio of maximum diameter of plastron plate to length of corona $0.51-0.71$.

Abdomen: Shagreen (Fig. 18) mainly consisting of bifid and multifid spinules on tergites I-VIII and simple spinules on tergite IX. Segments I-VI each with 2 pairs of flattened L-setae; $\mathrm{L}_{1}$-seta on segment IV $43-63 \mu \mathrm{m}$ long and 0.11-0.16 times as long as segment length. Segment VII with 4 pairs of lateral taeniae on about posterior 0.30; segment VIII with 5 pairs of lateral taeniae on about posterior 0.40 (Fig. 19). Segment VIII with posterolateral spines $8-13 \mu \mathrm{m}$ long (Fig. 20). Anal lobe $285-350 \mu \mathrm{m}$ long and 1.7-2.2 times as long as broad. Male genital sac 0.67-0.75 times as long as anal lobe. 


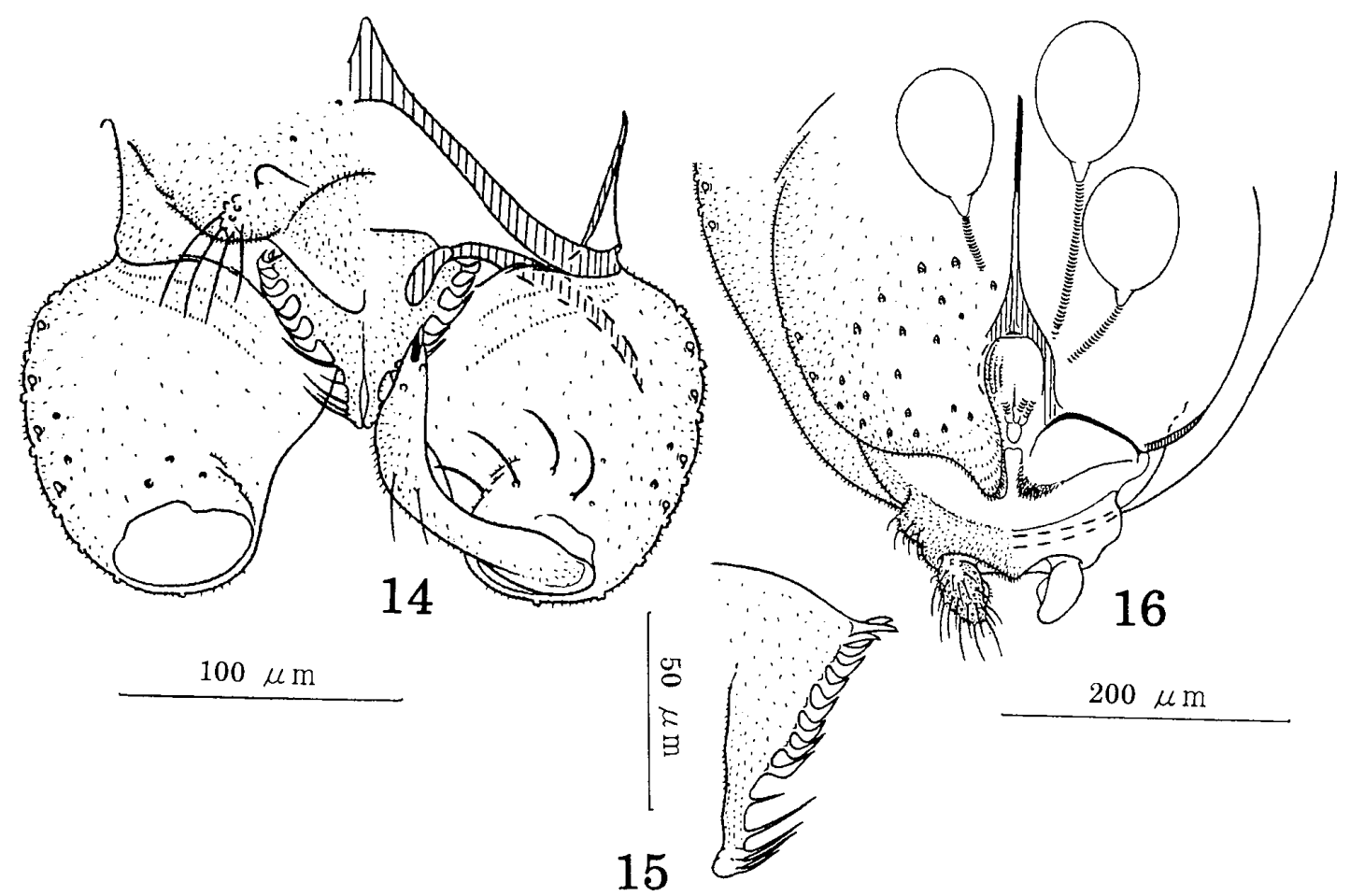

Figs 14-16. Conchapelopia okisimilis Sasa, 1990, adult males, SUM-IC-T 0091 (14), 0111 (15), and adult female, SUM-IC-T 0109 (16). 14, Hypopygium, dorsal view; 15, median volsella, dorsal view; 16, genitalia, ventral view.

Fourth instar larva $(\mathrm{n}=8$, unless otherwise stated). Body length $4.0-4.5 \mathrm{~mm}$.

Coloration: Head and claws of posterior parapod yellow and body yellowishwhite in life.

Head: Length $570-600 \mu \mathrm{m}$; cephalic index 0.58. Dorsal cephalic seta $S_{8}$ lateral to dorsal sensory pore and close to $S_{7}$; ventral cephalic seta $S_{10}$ posteromedial to $S_{9}$ and anteromedial to ventral sensory pore. Lengths of antennal segments I-IV (in $\mu \mathrm{m}, \mathrm{n}=7$ ) 203-240 (225), 48-55 (51), 8-9 (8), and 6-7 (6), respectively; antennal ratio 3.3-3.5 (Fig. 21). Antennal segment I 9.6-10.6 times as long as its basal width, with ring organ positioned $0.30-0.33$ of way from apex; blade $58-65 \mu \mathrm{m}$ long, $5.6-6.3$ times as long as its basal ring and reaching to apex of segment III; accessory blade 58-64 $\mu \mathrm{m}$ long. Antennal segment II 10.3-11.1 times as long as its basal width; style $10-13 \mu \mathrm{m}$ long, reaching to middle of segment IV; Lauterborn organ $4-5 \mu \mathrm{m}$ long. Mandible (Fig. 22) 110-140 $\mu \mathrm{m}$ long. Basal segment of maxillary palp $40-48 \mu \mathrm{m}$ long, $3.2-4.0$ times of its basal width, with ring organ positioned $0.21-0.25$ of way from apex. M-appendage (Fig. 23) with 7 or 8 rows of granules on pseudoradula. Ligula (Fig. 24) $75-95 \mu \mathrm{m}$ long and almost twice as long as its broadest width. Paraligula bifid and 35-43 $\mu \mathrm{m}$ long; fork positioned at about mid length. Pecten hypopharyngis with 16-20 teeth on each side.

Body: Procercus 3.2-4.4 times as long as wide, with 7 anal setae. Anal tubules about 4 times as long as wide, tapering to pointed apex (Fig. 25).

Distribution. Japan (Fukushima, Shizuoka, Toyama, Ehime, and Okinawa Prefectures). 

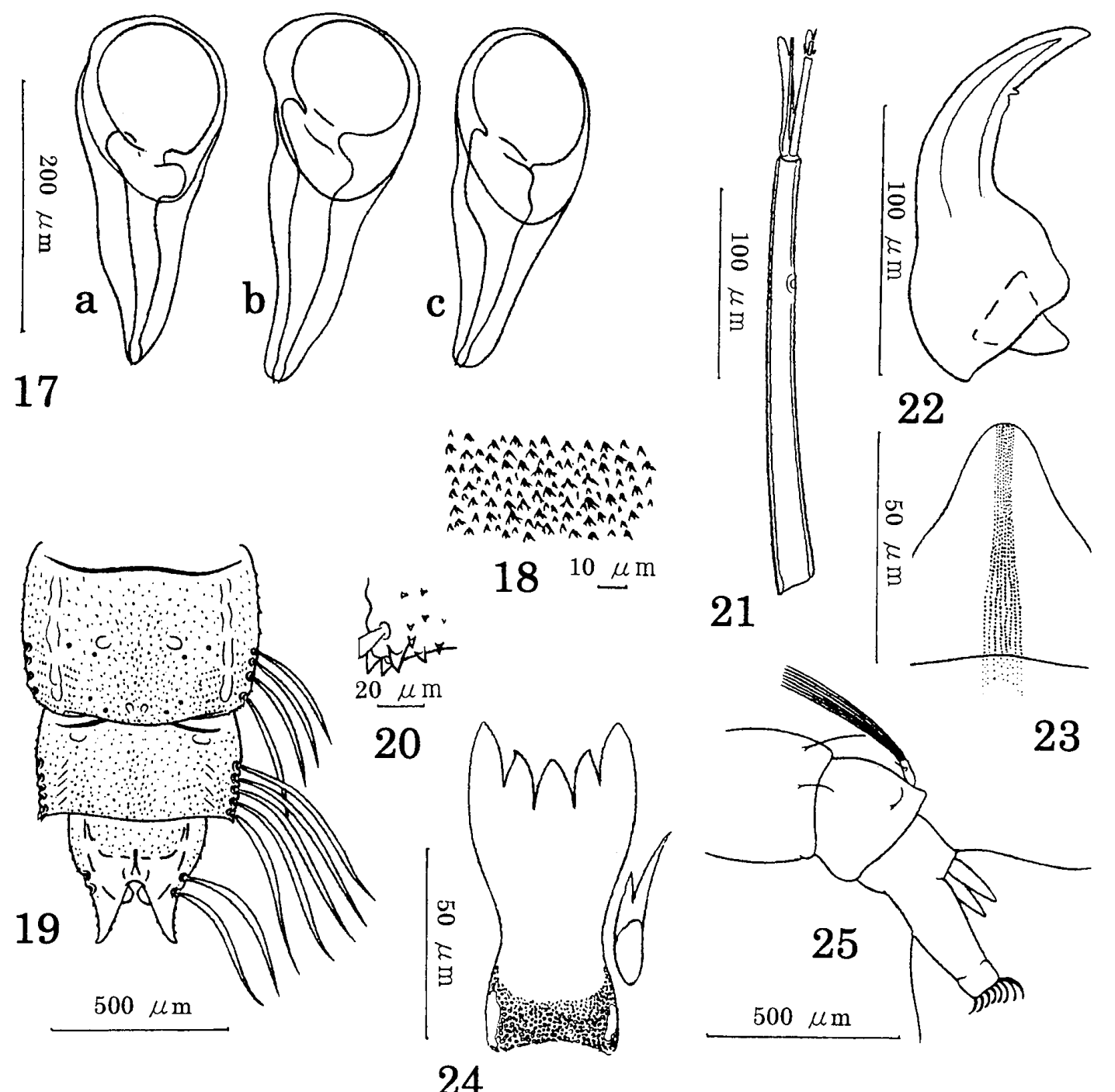

\section{4}

Figs 17-25. Conchapelopia okisimilis Sasa, 1990, pupal exuviae, SUM-IC-T 0082 (17a), 0083 (17b), 0109 (17c), 0084 (18-20), and larval exuviae, SUM-IC-T 0097 (21-25). 17a-c, Thoracic horn, showing morphological variation; 18, shagreen on posteromedial part of abdominal tergite IV; 19, abdominal segments VII-IX, dorsal view (only right lateral setae shown); 20, posterolateral spines on abdominal segment VIII; 21, antenna; 22, mandible; 23, M-appendage; 24, ligula and paraligula; 25, posterior body segments, lateral view.

Remarks. Sasa (1990a) described a new species, Conchapelopia okisimilis, based on its holotype specimen which was raised from a larva in the laboratory. In the same year, Sasa (1990b) described another new species, C. jintualba, based on its holotype from Toyama City. He (1990b) distinguished C. jintualba from C. okisimilis by the different coloration: $C$. jintualba has an almost completely white body, whereas $C$. okisimilis has brown markings on the scutum and postnotum and brownish-yellow bands on abdominal tergites II-VII in the male. However, the morphology of the hypopygium is very similar in the two taxa. It is now generally known that the body coloration of Conchapelopia species varies individually, and thus is not reliable in species differentiation. In light of the close similarity in the 
morphology of the hypopygium, it is reasonable to consider $C$. jintualba to be a junior synonym of $C$. okisimilis.

Conchapelopia okisimilis much resembles the North American species $C$. varna Roback, 1981 in that the hypopygium lacks a digitiform appendage on the median volsella and the dorsolateral processes are widely spaced, but it differs from $C$. varna in having long beards on tarsomere 1 of the foreleg, and lacking a tarsal brush of strong setae on the middle leg. According to Roback (1981), the male of $C$. varna has no beard on the foretarsus and a distinct tarsal brush on tarsomere 3 of the middle leg. Furthermore, the morphology of the pupa is different between the two species. That of Conchapelopia okisimilis differs from that of $C$. varna in having a nearly circular plastron plate in the thoracic horn (length/width 0.9-1.4, usually about 1.0). In C. varna, the plastron plate is distinctly elliptical (length/width 1.6-2.0).

Conchapelopia shikotuensis Sasa, 1990

[Japanese name: Shikotsu-torafu-yusurika]

(Figs 26-35, Table 4)

Conchapelopia melanops: Sasa 1988: 52. [Not Conchapelopia melanops (Meigen, 1818)]

Pentaneura japonica: Sasa 1988: 53. [Not Pentaneura japonica Tokunaga, 1937]

Conchapelopia shikotuensis Sasa, 1990b: 53.

Conchapelopia japonica: Sasa and Okazawa 1991: 65; 1992: 208. [Not Conchapelopia japonica (Tokunaga, 1937)]

Conchapelopia ginzanvewea Sasa and Suzuki, 2001b: 25. Syn. nov.

Material examined. Holotype of Conchapelopia shikotuensis: ô (NSMT-I-Dip 4607), labeled "No. A121: 20", Lake Shikotsu, Hokkaido, 12 June 1986. Holotype of Conchapelopia ginzanvewea: o (NSMT-I-Dip 5394), labeled "No. 403: 87", Ginzan Mountain, Hokkaido, 2 September 2000. Non-types: 1 if with its pupal exuviae (SUM-IC-T 0144), fontal stream in Shiraiwa, Iwaki City, Fukushima Prefecture, 3 February 1990 (adult emerged on 20 February 1990); 19 with its pupal exuviae (SUM-IC-T 0145), same locality, 1 August 1990 (adult emerged on 10 August 1990); 10 with its pupal exuviae (SUM-IC-T 0146), same locality, 10 August 1992 (adult emerged on 25 August 1992); 10 with its pupal exuviae (SUM-IC-T 0147), Ôpisa River in Iwaki City, 19 August 1999 (adult emerged on 28 August 1999); 10 with its pupal exuviae (SUM-IC-T 0148), Ide River in Naraha Town, Fukushima Prefecture,

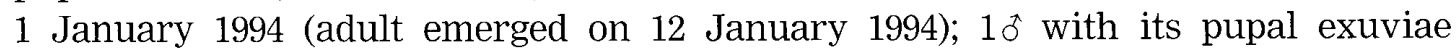
(SUM-IC-T 0149), Asami River in Hirono Town, Fukushima Prefecture, 19 August 1999 (adult emerged on 26 August 1999); 1 औ, 2 pupae, with the male's pupal exuviae and all their larval exuviae (SUM-IC-T 0150-0152), same locality, 15 August 2001 (adult emerged on 26 August 2001); $1 \delta^{\text {t }}$ with its pupal and larval exuviae (SUM-IC-T 0153), same locality, 5 May 2002 (adult emerged on 21 May 2002); 10 with its pupal exuviae (SUM-IC-T 0154), same locality, 15 August 2002 (adult emerged on $20 \mathrm{Au}$ gust 2002); 1 o with its pupal exuviae (SUM-IC-T 0155), fontal stream in Shimokawahara, Shizuoka City, Shizuoka Prefecture, 11 May 1995 (adult emerged on 22 May 1995); 3 o oै with 1 male's pupal and larval exuviae (SUM-IC-T 0156-0158), 
same locality, 22 February 1999 (adults emerged on 12 and 13 March 1999); 1 o, 1 \%, with the female's pupal exuviae (SUM-IC-T 0159, 0160), Harada River in Shizuoka City, 20 August 2000 (adults emerged on 28 and 29 August 2000); 1 (SUM-IC-T 0161), Uchimaki River in Shizuoka City, 5 October 2001.

Description. Male ( $\mathrm{n}=12$, unless otherwise stated). Body length 3.4-5.1 mm.

Coloration: Body predominantly pale yellow with dark markings. Thorax darkened on anepisternum II, preepisternum, and postnotum; scutum with 4 pairs of dark spots along vittae. Abdominal tergites III-VI and VIII each with narrow dark band anteriorly, and tergite VII broadly darkened; dark band on tergite VI weak in some specimens. Wings without any markings. All legs distinctly darkened on apex of femur and both ends of tibia; tarsomeres $4-5$ or just 5 slightly darkened in some specimens.

Head: Temporals 14-22, uniserial, partly biserial. Antenna with apical seta 45-70 $\mu \mathrm{m}$ long; antennal ratio 1.7-2.0. Clypeus rounded, with 18-33 setae. Lengths of palpomeres 1-5 (in $\mu \mathrm{m}$ ) 63-100 (74), 88-145 (111), 170-240 (197), 195-270 (217), and 285-350 (316), respectively.

Thorax: Antepronotum with 3-9 lateral setae on each lobe. Scutal tubercle $10-23 \mu \mathrm{m}$ high. Acrostichals 43-61, biserial between median scutal vittae; dorsocentrals 17-27, medially uniserial, anteriorly and posteriorly bi- or triserial; humerals 6-14; prealars 16-24, uniserial, partly multiserial; supraalars 1-3, usually 2; no preepisternals. Scutellum with $36-46$ setae. Wings $2.3-3.6 \mathrm{~mm}$ long; venarum ratio 0.87-0.93; squama with 30-50 setae. All legs with long tibial spurs each bearing 7-10 lateral teeth; ratio of inner spur length to outer spur length 1.0-1.3 in middle leg, 1.5-1.8 in hind leg; hind leg with tibial comb of $6-8$, usually 7 , spines. Tarsal beard moderately long; bristle ratio 5.2-7.9 in foreleg, 5.3-6.7 in middle leg, 5.0-7.1 in hind leg; middle leg without tarsal brush. Tarsal claws pointed apically in fore- and hind legs, trifid in middle leg, and each claw with several short spines basoventrally; pulvilli absent. Lengths and ratios of leg segments as shown in Table 4.

Hypopygium (Fig. 26): Tergite IX with 14-26 setae, many of them concentrated posterolaterally; lateral tubercle indistinct. Gonocoxite $158-205 \mu \mathrm{m}$ long, with 5-8, usually 5, large preapical setae. Median volsella (Fig. 27) slender, $83-113 \mu \mathrm{m}$ long, 2.1-2.5 times as long as wide, with digitiform appendage basolaterally and 2-6 gradually tapered processes on about apical 0.20 ; ventral lobe absent.

Female $(\mathrm{n}=4$, unless otherwise stated). Body length $2.3-3.3 \mathrm{~mm}$.

Coloration: Similar to male, but abdomen entirely pale yellow.

Head: Temporals 17-27 in number. Antenna with apical seta 50-65 $\mu \mathrm{m}$ long; terminal flagellomere almost as long as or slightly longer than preceding 3 flagellomeres together; antennal ratio 0.31-0.34. Clypeus with 19-35 setae. Lengths of palpomeres 1-5 (in $\mu \mathrm{m}$ ) 70-85 (78), 88-133 (114), 155-225 (195), 180-250 (220), and 300343 (323), respectively.

Thorax: Antepronotum with 4-8 lateral setae on each lobe. Scutal tubercle $10-15 \mu \mathrm{m}$ high. Acrostichals 52-66 in number, dorsocentrals $23-37$, humerals $15-24$, prealars 18-28, supraalars 2-3 (usually 2), no preepisternals. Scutellum with 42-66 setae. Wings 2.1-3.0 $\mathrm{mm}$ long; venarum ratio 0.88-0.90; squama with $36-51$ setae. All legs with tibial spurs each bearing 8-10 lateral teeth; ratio of inner spur length to outer spur length 1.0-1.2 in middle leg, 1.6-1.8 in hind leg. All tarsal claws pointed apically, with short basoventral spines; pulvilli absent. Lengths and ratios of leg segments as shown in Table 4. 


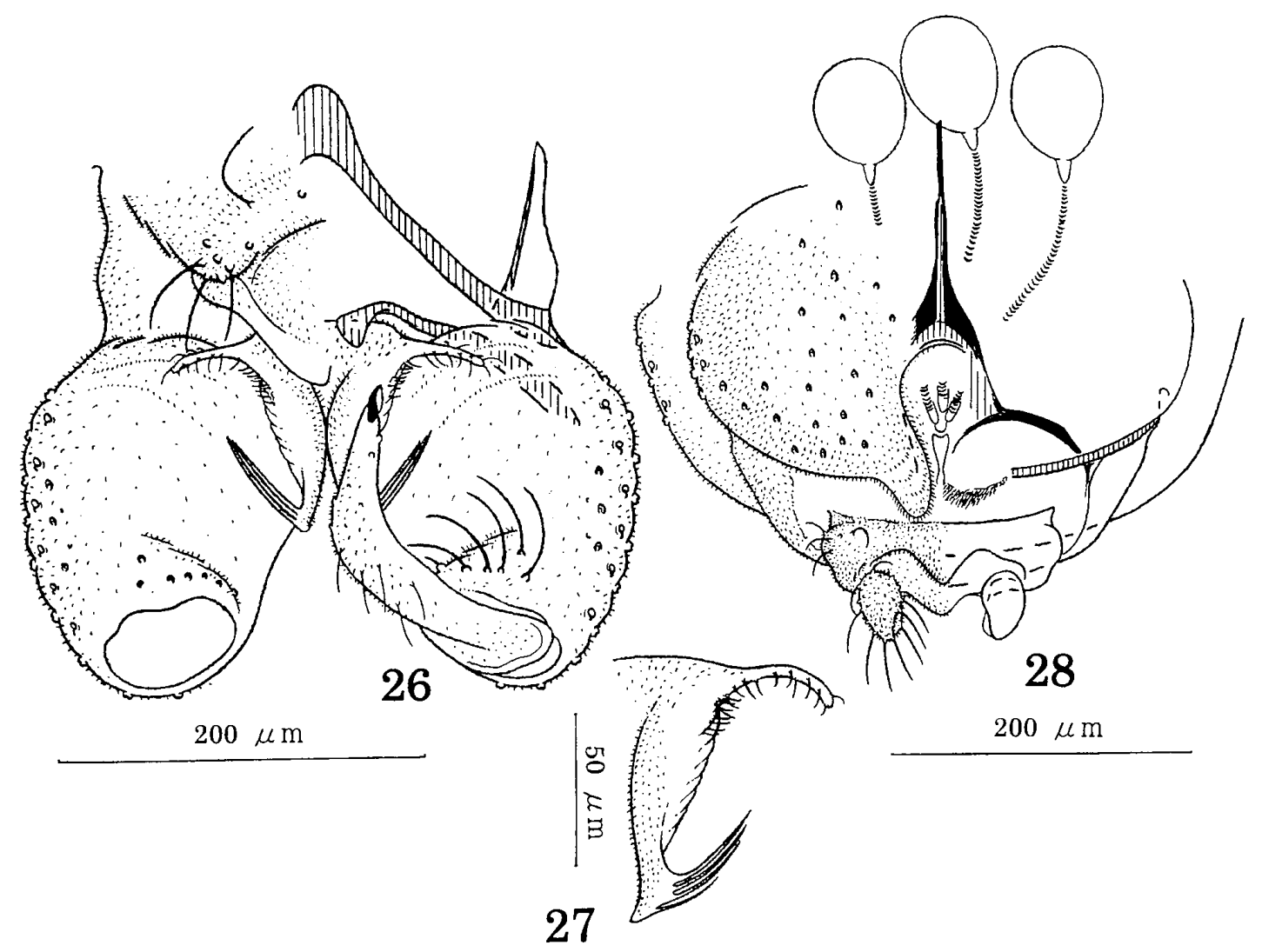

Figs 26-28. Conchapelopia shikotuensis Sasa, 1990, adult males, SUM-IC-T 0147 (26), 0157 (27), and adult female, SUM-IC-T 0145 (28). 26, Hypopygium, dorsal view; 27, median volsella, dorsal view; 28, genitalia, ventral view.

Genitalia (Fig. 28): Gonotergite IX without setae. Labium with apical microtrichia. Seminal capsule pale, oval, $78-95 \mu \mathrm{m}$ long and $63-80 \mu \mathrm{m}$ wide. Segment $\mathrm{X}$ with $5-12$ setae on each side.

Pupa ( $\mathrm{n}=14$, unless otherwise stated). Body length 4.4-6.5 mm.

Coloration: Exuviae pale brown, with dark scar and apophyses on abdomen.

Cephalothorax: Thoracic horn (Fig. 29a-c) 270-380 $\mu \mathrm{m}$ long and 1.9-2.1 times as long as broad. Plastron plate oval and large; ratio of its maximum diameter to length of thoracic horn $0.38-0.61$. Corona occupying apical $0.41-0.62$ of thoracic horn; ratio of maximum diameter of plastron plate to length of corona 0.91-0.97. Respiratory atrium swollen apically, amoeboid and infuscate.

Abdomen: Shagreen (Fig. 30) mainly consisting of multifid spinules on tergites I-VIII and simple spinules on tergite IX. Segments I-VI each with 2 pairs of flattened L-setae; $\mathrm{L}_{1}$-seta on segment IV $63-80 \mu \mathrm{m}$ long and $0.13-0.17$ times of segment length. Segment VII with 4 pairs of lateral taeniae on about posterior 0.40; segment VIII with 5 pairs of lateral taeniae on about posterior half (Fig. 31). Anal lobe $390-520 \mu \mathrm{m}$ long and 1.9-2.3 times as long as broad. Male genital sac 0.59-0.67 times as long as anal lobe.

Fourth instar larva $(\mathrm{n}=5$, unless otherwise stated).

Coloration: Head and claws of posterior parapod yellow and body yellowishwhite in life. 
Table 4. Lengths (in $\mu \mathrm{m}$ ) and ratios of leg segments in 12 males and four females of Conchapelopia shikotuensis Sasa, 1990.

\begin{tabular}{|c|c|c|c|c|c|}
\hline & Coxa & Trochanter & Femur & Tibia & Tarsomere 1 \\
\hline \multicolumn{6}{|l|}{ Male } \\
\hline Foreleg & $\begin{array}{c}220-320 \\
(260)\end{array}$ & $\begin{array}{c}170-240 \\
(200)\end{array}$ & $\begin{array}{c}940-1360 \\
(1080)\end{array}$ & $\begin{array}{c}1160-1700 \\
(1330)\end{array}$ & $\begin{array}{c}930-1310 \\
(1050)\end{array}$ \\
\hline Middle leg & $\begin{array}{c}360-500 \\
(420)\end{array}$ & $\begin{array}{c}120-180 \\
(140)\end{array}$ & $\begin{array}{c}980-1530 \\
(1170)\end{array}$ & $\begin{array}{c}1000-1530 \\
(1150)\end{array}$ & $\begin{array}{c}580-870 \\
(690)\end{array}$ \\
\hline Hind leg & $\begin{array}{c}300-450 \\
(350)\end{array}$ & $\begin{array}{c}120-150 \\
(130)\end{array}$ & $\begin{array}{c}870-1330 \\
(1050)\end{array}$ & $\begin{array}{c}1250-1960 \\
(1480)\end{array}$ & $\begin{array}{c}870-1300 \\
(1020)\end{array}$ \\
\hline \multicolumn{6}{|l|}{ Female } \\
\hline Foreleg & $\begin{array}{c}220-300 \\
(260)\end{array}$ & $\begin{array}{c}160-220 \\
(200)\end{array}$ & $\begin{array}{c}880-1150 \\
(1030)\end{array}$ & $\begin{array}{c}1140-1510 \\
(1320)\end{array}$ & $\begin{array}{c}800-1110 \\
(950)\end{array}$ \\
\hline Middle leg & $\begin{array}{c}360-480 \\
(430)\end{array}$ & $\begin{array}{c}120-150 \\
(140)\end{array}$ & $\begin{array}{c}950-1330 \\
(1160)\end{array}$ & $\begin{array}{c}1030-1390 \\
(1210)\end{array}$ & $\begin{array}{c}590-820 \\
(710)\end{array}$ \\
\hline \multirow[t]{2}{*}{ Hind leg } & $\begin{array}{c}300-390 \\
(360)\end{array}$ & $\begin{array}{c}120-150 \\
(140)\end{array}$ & $\begin{array}{c}850-1170 \\
(1030)\end{array}$ & $\begin{array}{c}1210-1800 \\
(1520)\end{array}$ & $\begin{array}{c}710-1070 \\
(950)\end{array}$ \\
\hline & Tarsomere 2 & Tarsomere 3 & Tarsomere 4 & Tarsomere 5 & Leg ratio \\
\hline \multicolumn{6}{|l|}{ Male } \\
\hline Foreleg & $\begin{array}{c}490-700 \\
(560)\end{array}$ & $\begin{array}{c}340-490 \\
(400)\end{array}$ & $\begin{array}{c}240-350 \\
(280)\end{array}$ & $\begin{array}{c}140-190 \\
(160)\end{array}$ & $0.74-0.82$ \\
\hline Middle leg & $\begin{array}{c}280-390 \\
(330)\end{array}$ & $\begin{array}{c}220-310 \\
(250)\end{array}$ & $\begin{array}{c}180-250 \\
(210)\end{array}$ & $\begin{array}{c}110-140 \\
(120)\end{array}$ & $0.55-0.63$ \\
\hline Hind leg & $\begin{array}{c}470-740 \\
(570)\end{array}$ & $\begin{array}{c}360-570 \\
(440)\end{array}$ & $\begin{array}{c}250-370 \\
(290)\end{array}$ & $\begin{array}{c}130-170 \\
(150)\end{array}$ & $0.66-0.71$ \\
\hline \multicolumn{6}{|l|}{ Female } \\
\hline Foreleg & $\begin{array}{c}400-590 \\
(500)\end{array}$ & $\begin{array}{c}260-400 \\
(350)\end{array}$ & $\begin{array}{c}200-290 \\
(250)\end{array}$ & $\begin{array}{c}110-170 \\
(150)\end{array}$ & $0.66-0.77$ \\
\hline Middle leg & $\begin{array}{c}280-400 \\
(340)\end{array}$ & $\begin{array}{c}190-290 \\
(250)\end{array}$ & $\begin{array}{c}150-210 \\
(190)\end{array}$ & $\begin{array}{c}90-130 \\
(120)\end{array}$ & $0.57-0.59$ \\
\hline Hind leg & $\begin{array}{c}400-620 \\
(540)\end{array}$ & $\begin{array}{c}310-470 \\
(410)\end{array}$ & $\begin{array}{c}210-310 \\
(260)\end{array}$ & $\begin{array}{c}110-160 \\
(150)\end{array}$ & $0.59-0.67$ \\
\hline
\end{tabular}

Lengths are given as ranges and means (in parentheses).

Head: Length 760-790 $\mu \mathrm{m}$; cephalic index 0.58. Dorsal cephalic seta $\mathrm{S}_{8}$ lateral to dorsal sensory pore and close to $S_{7}$; ventral cephalic seta $S_{10}$ posteromedial to $S_{9}$ and anteromedial to ventral sensory pore (Fig. 32). Lengths of antennal segments I-IV (in $\mu \mathrm{m}$ ) 253-268 (264), 41-48 (45), 6-8 (7), and 4-5 (5), respectively; antennal ratio 4.5-4.9 (Fig. 33). Antennal segment I 10.1-11.3 times as long as its basal width, with ring organ positioned $0.30-0.35$ of way from apex; blade $49-55 \mu \mathrm{m}$ long, 3.7-3.9 times as long as its basal ring and extending beyond apex of segment III; accessory blade almost as long as blade. Antennal segment II 9.0-9.5 times as long as its basal width; style $8-10 \mu \mathrm{m}$ long, reaching to middle of segment IV; Lauterborn organ $4-5 \mu \mathrm{m}$ long. Mandible $128-148 \mu \mathrm{m}$ long. Basal segment of maxillary palp (Fig. 34) $45-55 \mu \mathrm{m}$ long, 3.6-4.0 times as long as its basal width, with ring organ positioned $0.21-0.25$ of way from apex. M-appendage with 7 or 8 rows of granules on pseudo- 

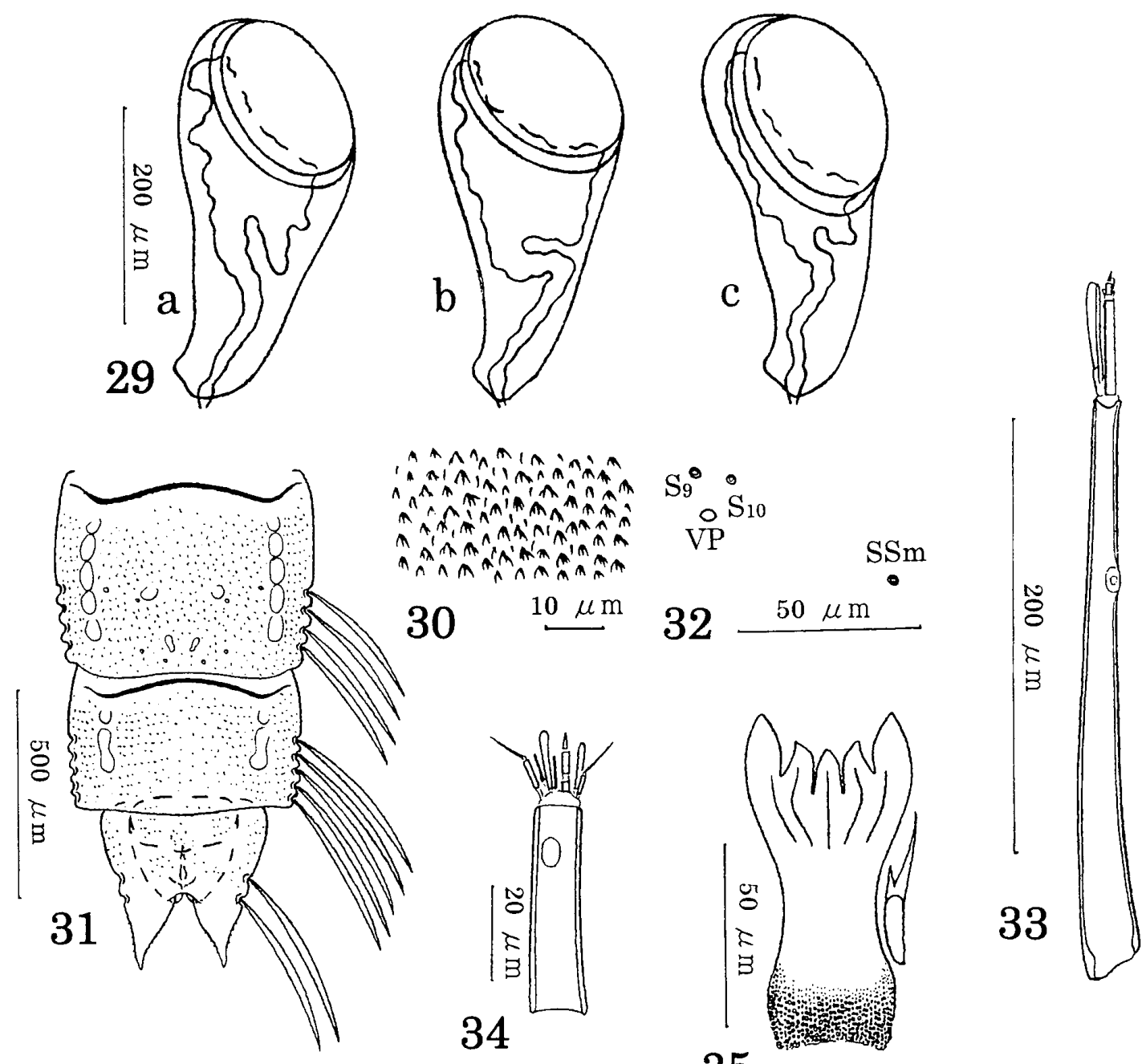

Figs 29-35. Conchapelopia shikotuensis Sasa, 1990, pupal exuviae, SUM-IC-T 0146 (29a), 0149 (29b), 0155 (29c), 0154 (30, 31), and larval exuviae, SUM-IC-T 0153 (32-35). 29a-c, Thoracic horn, showing morphological variation; 30, shagreen on posteromedial part of abdominal tergite IV; 31, abdominal segments VII-IX, dorsal view (only right lateral setae shown); 32, arrangement of ventral cephalic setae and sensory pore; 33, antenna; 34, maxillary palp; 35, ligula and paraligula. Abbreviations as in Figs 7-13.

radula. Ligula (Fig. 35) $90-100 \mu \mathrm{m}$ long and almost twice as long as its broadest width. Paraligula bifid, $43-45 \mu \mathrm{m}$ long; fork positioned $0.44-0.50$ of way from base. Pecten hypopharyngis with 19-21 teeth on each side.

Body: Procercus 3.5-3.8 times as long as wide, with 7 anal setae.

Distribution. Japan (Hokkaido, Fukushima, Shizuoka, and Toyama Prefectures).

Remarks. Sasa (1988) recorded "Conchapelopia melanops" from Lake Shikotsu, Hokkaido, Japan, but later Sasa (1990b) proposed a new name Conchapelopia shikotuensis for his "C. melanops". The species differentiation was mainly based on the scutal marking pattern. Later, Sasa and Suzuki (2001a) further described a new species $C$. ginzanvewea based on the holotype from Ginzan Moun- 
tain, Hokkaido. Reexamination of the holotypes of the two taxa has shown that they are identical with little doubt. Although Sasa (1990b) noted "leg segments yellow", it is evident that the legs of the holotype of $C$. shikotuensis are darkened at the apical end of the femur and both ends of tibia as in the holotype of Conchapelopia ginzanvewea. The hypopygium is provided with a slender median volsella (Fig. 27) in the holotypes of both $C$. shikotuensis and $C$. ginzanvewea. Conchapelopia shikotuensis is thus the senior synonym of $C$. ginzanvewea.

Sasa (1988) recorded "Conchapelopia japonica (as Pentaneura)" on the basis of a single female specimen from Lake Toya, Hokkaido. He mentioned that his female specimen had dark rings on the femora and tibiae. Later, Sasa and Okazawa (1991) reported males of " $C$. japonica" and noted (p. 67), "On the other hand, the species recorded by Tokunaga (1937) by female collected in Kyoto by the name of Pentaneura japonica is exactly the same in morphology as those of the present species, excepting that the presence of brown rings on femora and tibiae, which had probably been overlooked by the original author." However, the specimens referred to $C$. japonica by Sasa (1988) and Sasa and Okazawa (1991) most probably represent $C$. shikotuensis because of the presence of dark rings on the femora and tibiae. Tokunaga (1937b) specifically noted that all legs of $C$. japonica (as Pentaneura) were entirely white (see also Tokunaga 1937b, fig. 73 ). It has been confirmed that $C$. japonica has no distinct markings on the femora and tibiae.

Dark-ringed femora occur also in Conchapelopia cygnus (Kieffer, 1923), C. trifascia (Freeman, 1954), C. falcistylus Chaudhuri and Debnath, 1983, C. insolens Murray, 1995, and $C$. amamiaurea, as well as $C$. shikotuensis. Among these species, $C$. shikotuensis, $C$. cygnus, and $C$. insolens are very similar to one another in their well-developed digitiform appendage on the hypopygial median volsella. Conchapelopia shikotuensis, however, differs from the other two species in having plain wings. According to Freeman (1955) and Murray (1995), C. cygnus and C. insolens have dark-banded wings.

Conchapelopia togamaculosa Sasa and Okazawa, 1992 [Japanese name: Toga-torafu-yusurika]

(Figs 36-46, Table 5)

Conchapelopia togamaculosa Sasa and Okazawa, 1992: 209.

Material examined. Holotype of Conchapelopia togamaculosa: $\hat{\alpha}$ (NSMT-I-Dip 4749), labeled "No. A188: 14", Toga River in Toga Village, Toyama Prefecture, 11 September 1990. Non-types: $6 \delta^{\circ}, 2 q q$, with 5 of their pupal and 1 of their larval exuviae (SUM-IC-T 0116-0123), Ihara River in Shizuoka City, Shizuoka Prefecture, 10 June 1989 (adults emerged on 15-20 June 1989); 200 with 1 of their pupal exuviae (SUM-IC-T 0124, 0125), same locality, 25 June 1989 (adults emerged on 1 and 7 July 1989); $1 \delta^{\text {to }}$ with its pupal exuviae (SUM-IC-T 0126), small stream in Ashikubo, Shizuoka City, 10 February 1999 (adult emerged on 4 March 1999); 1ठ with its pupal exuviae (SUM-IC-T 0127), fontal stream in Shimokawahara, Shizuoka City, 22 February 1999 (adult emerged on 15 March 1999); $20^{\star}{ }^{*}$ with 1 of their pupal exuviae (SUM-IC-T 0128, 0129), small stream in Yanbara, Shimizu, Shizuoka City, 21 July 1999 (adults emerged on 27 and 30 July 1999); 1 (SUM-IC-T 0130), small stream in 


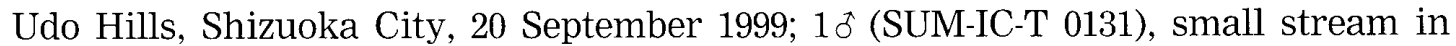
Miyagase, Kiyokawa Village, Kanagawa Prefecture, 23 September 1995; 1 ㅇ (SUMIC-T 0132), small stream in Yaguki, Iwaki City, Fukushima Prefecture, 15 August 2001; 500,1 \%, with 5 of their pupal and 2 of their larval exuviae (SUM-IC-T 0133-0138), Asami River in Hirono Town, Fukushima Prefecture, 15 August 2001 (adults emerged on 20 August-11 September 2001); $20 \hat{0}, 2 \circ+$, with all their pupal exuviae (SUM-IC-T 0139-0142), same locality, 5 May 2002 (adults emerged on 20-26

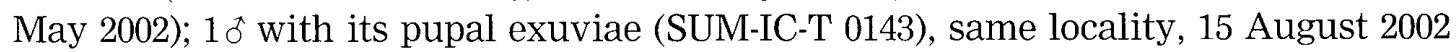
(adult emerged on 22 August 2002).

Description. Male $(\mathrm{n}=22$, unless otherwise stated). Body length $3.2-4.0 \mathrm{~mm}$.

Coloration: Body predominantly yellow with dark markings. Clypeus markedly dark. Thorax dark on anepisternum II, preepisternum, and postnotum; scutum with 4 pairs of dark spots along vittae. Abdominal tergites II-VIII each with anterior dark band, this being narrow on tergites II-VI, broad on tergites VII and VIII; dark bands on tergites II, VI, and VIII weak in some specimens. Hypopygium dark on gonocoxite. Wings (Fig. 36) with 3 dark bands, these bands weak in some specimens. Legs yellow.

Head: Temporals 15-22, uniserial, partly biserial. Antenna with apical seta 43-63 $\mu \mathrm{m}$ long; antennal ratio 1.8-2.0. Clypeus rounded, with 18-32 setae. Lengths of palpomeres 1-5 (in $\mu \mathrm{m}, \mathrm{n}=15)$ 55-88 (71), 88-115 (100), 150-195 (176), 175-225 (205), and 230-320 (289), respectively.

Thorax: Antepronotum with 3-9 lateral setae on each lobe. Scutal tubercle 10-18 $\mu \mathrm{m}$ high. Acrostichals 40-63, biserial between median scutal vittae; dorsocentrals 18-27, medially uniserial, anteriorly and posteriorly bi- or triserial; humerals 5-15; prealars 15-26, uniserial, partly multiserial; 1 supraalar; no preepisternals. Scutellum with $30-45$ setae. Wings $2.2-2.8 \mathrm{~mm}$ long; venarum ratio $0.88-0.93$; squama with $30-51$ setae. All legs with long tibial spurs each bearing 6-9 lateral teeth; ratio of inner spur length to outer spur length 1.0-1.1 in middle leg, 1.7-2.2 in hind leg; hind leg with tibial comb of 6-8, usually 7 , spines. Tarsal beard moderately long; bristle ratio 4.8-7.1 in foreleg, 4.3-7.3 in middle leg, 4.5-6.8 in hind leg; middle leg with tarsal brush of 12-21 strong setae on tarsomere 3. Tarsal claws pointed apically in fore- and hind legs, trifid in middle leg, and each claw with several short spines basoventrally; pulvilli absent. Lengths and ratios of leg segments as shown in Table 5 .

Hypopygium (Fig. 37): Tergite IX with 14-35 setae mostly on lateral tubercles. Gonocoxite 125-163 $\mu \mathrm{m}$ long, with 4 large preapical setae. Median volsella (Fig. 38) 73-110 $\mu \mathrm{m}$ long, projecting triangularly at basolateral corner, with 6-9 tightly arranged and partially expanded dorsolateral processes on about basal $1 / 3,2-6$ well-spaced and gradually tapered processes on middle $1 / 3$, and $3-6$ partially expanded and 1-3 gradually tapered processes, these shortening towards apex, on apical 1/3; ventral lobe pubescent, rather small, 0.13-0.24 times as long as median volsella; digitiform appendage absent.

Female $(\mathrm{n}=6$, unless otherwise stated). Body length $2.5-3.1 \mathrm{~mm}$.

Coloration: Similar to male, but abdomen entirely pale yellow.

Head: Temporals 16-19 in number. Antenna with apical seta 48-63 $\mu \mathrm{m}$ long; terminal flagellomere almost as long as preceding 3 flagellomeres together; antennal ratio 0.29-0.35. Clypeus with 26-31 setae. Lengths of palpomeres 1-5 (in $\mu \mathrm{m}$ ) 50-100 (73), 90-115 (108), 163-207 (183), 188-235 (215), and 263-335 (291), respectively. 


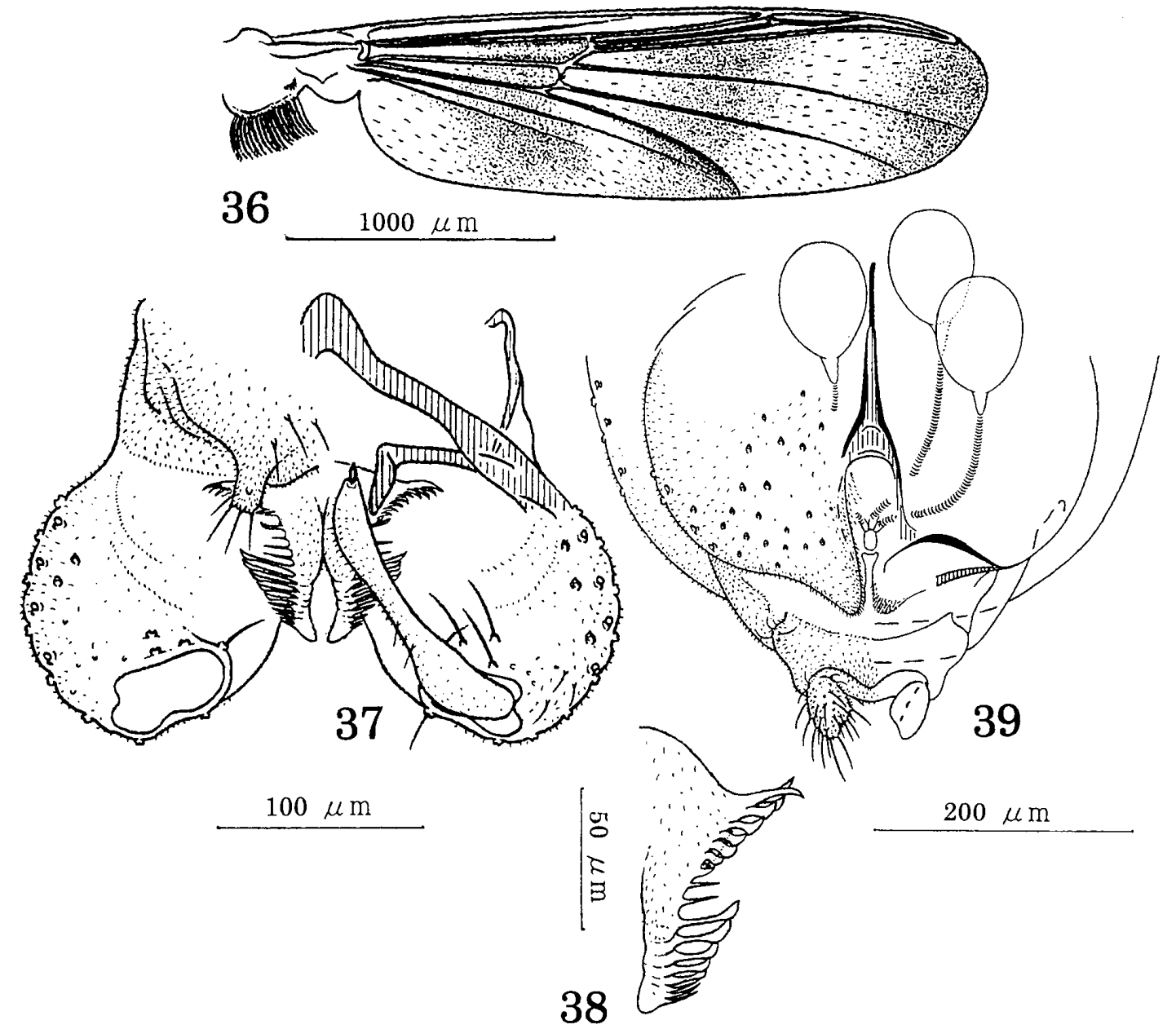

Figs 36-39. Conchapelopia togamaculosa Sasa and Okazawa, 1992, adult males, SUM-IC-T 0143 (36, 37), 0128 (38), and adult female, SUM-IC-T0041 (39). 36, Wing; 37, hypopygium, dorsal view; 38 , median volsella, dorsal view; 39 , genitalia, ventral view.

Thorax: Antepronotum with 2-4 lateral setae on each lobe. Scutal tubercle $10-18 \mu \mathrm{m}$ high. Acrostichals 49-69 in number, dorsocentrals $23-35$, humerals $16-22$, prealars 18-28, supraalars 1-2 (usually 1), no preepisternals. Scutellum with 35-52 setae. Wings $2.1-2.8 \mathrm{~mm}$ long; venarum ratio 0.89-0.92; squama with $34-44$ setae. All legs with tibial spurs each bearing 6-8 lateral teeth; ratio of inner spur length to outer spur length 1.0-1.2 in middle leg, 1.7-1.9 in hind leg. All tarsal claws pointed apically, each with short basoventral spines; pulvilli absent. Lengths and ratios of leg segments as shown in Table 5.

Genitalia (Fig. 39): Gonotergite IX without setae. Labium with apical microtrichia. Seminal capsule pale, oval, $88-103 \mu \mathrm{m}$ long and $63-85 \mu \mathrm{m}$ wide. Segment $\mathrm{X}$ with 4-10 setae on each side.

Pupa $(\mathrm{n}=19$, unless otherwise stated). Body length $4.3-5.3 \mathrm{~mm}$.

Coloration: Exuviae pale brown, with dark scar and apophyses on abdomen.

Cephalothorax: Thoracic horn (Fig. 40a-c) slender, 260-325 $\mu \mathrm{m}$ long and 2.6-3.4 times as long as broad. Plastron plate oval and small; ratio of its maximum diameter to length of thoracic horn $0.13-0.24$. Corona occupying apical $0.42-0.60$ of tho- 
Table 5. Lengths (in $\mu \mathrm{m}$ ) and ratios of leg segments in 21 males and six females of Conchapelopia togamaculosa Sasa and Okazawa, 1992.

\begin{tabular}{|c|c|c|c|c|c|}
\hline & Coxa & Trochanter & Femur & Tibia & Tarsomere 1 \\
\hline \multicolumn{6}{|l|}{ Male } \\
\hline Foreleg & $\begin{array}{c}200-280 \\
(240)\end{array}$ & $\begin{array}{c}170-210 \\
(190)\end{array}$ & $\begin{array}{c}910-1110 \\
(1010)\end{array}$ & $\begin{array}{c}1000-1400 \\
(1260)\end{array}$ & $\begin{array}{c}900-1140 \\
(1020)\end{array}$ \\
\hline Middle leg & $\begin{array}{c}350-430 \\
(390)\end{array}$ & $\begin{array}{c}110-150 \\
(120)\end{array}$ & $\begin{array}{c}960-1240 \\
(1070)\end{array}$ & $\begin{array}{c}950-1210 \\
(1060)\end{array}$ & $\begin{array}{c}530-660 \\
(590)\end{array}$ \\
\hline Hind leg & $\begin{array}{c}290-370 \\
(330)\end{array}$ & $\begin{array}{c}110-140 \\
(120)\end{array}$ & $\begin{array}{c}870-1070 \\
(960)\end{array}$ & $\begin{array}{c}1170-1550 \\
(1340)\end{array}$ & $\begin{array}{c}840-1130 \\
(990)\end{array}$ \\
\hline \multicolumn{6}{|l|}{ Female } \\
\hline Foreleg & $\begin{array}{c}230-290 \\
(260)\end{array}$ & $\begin{array}{c}180-230 \\
(200)\end{array}$ & $\begin{array}{c}910-1120 \\
(1010)\end{array}$ & $\begin{array}{c}1180-1410 \\
(1320)\end{array}$ & $\begin{array}{c}940-1130 \\
(1060)\end{array}$ \\
\hline Middle leg & $\begin{array}{c}360-450 \\
(410)\end{array}$ & $\begin{array}{c}120-140 \\
(130)\end{array}$ & $\begin{array}{c}1010-1250 \\
(1130)\end{array}$ & $\begin{array}{c}1070-1310 \\
(1200)\end{array}$ & $\begin{array}{c}600-710 \\
(670)\end{array}$ \\
\hline \multirow[t]{2}{*}{ Hind leg } & $\begin{array}{c}310-400 \\
(350)\end{array}$ & $\begin{array}{c}120-150 \\
(140)\end{array}$ & $\begin{array}{c}900-1070 \\
(990)\end{array}$ & $\begin{array}{c}1230-1550 \\
(1380)\end{array}$ & $\begin{array}{c}860-1120 \\
(990)\end{array}$ \\
\hline & Tarsomere 2 & Tarsomere 3 & Tarsomere 4 & Tarsomere 5 & Leg ratio \\
\hline \multicolumn{6}{|l|}{ Male } \\
\hline Foreleg & $\begin{array}{c}480-610 \\
(530)\end{array}$ & $\begin{array}{c}320-430 \\
(370)\end{array}$ & $\begin{array}{c}210-330 \\
(270)\end{array}$ & $\begin{array}{c}130-160 \\
(140)\end{array}$ & $0.79-0.90$ \\
\hline Middle leg & $\begin{array}{c}260-320 \\
(290)\end{array}$ & $\begin{array}{c}210-270 \\
(240)\end{array}$ & $\begin{array}{c}180-230 \\
(200)\end{array}$ & $\begin{array}{c}100-120 \\
(110)\end{array}$ & $0.53-0.59$ \\
\hline Hind leg & $\begin{array}{c}450-610 \\
(520)\end{array}$ & $\begin{array}{c}350-460 \\
(400)\end{array}$ & $\begin{array}{c}240-310 \\
(260)\end{array}$ & $\begin{array}{c}120-150 \\
(130)\end{array}$ & $070-0.79$ \\
\hline \multicolumn{6}{|l|}{ Female } \\
\hline Foreleg & $\begin{array}{c}480-600 \\
(550)\end{array}$ & $\begin{array}{c}320-400 \\
(370)\end{array}$ & $\begin{array}{c}220-280 \\
(260)\end{array}$ & $\begin{array}{c}130-160 \\
(150)\end{array}$ & $0.80-0.82$ \\
\hline Middle leg & $\begin{array}{c}270-350 \\
(320)\end{array}$ & $\begin{array}{c}220-270 \\
(250)\end{array}$ & $\begin{array}{c}170-220 \\
(200)\end{array}$ & $\begin{array}{c}100-120 \\
(110)\end{array}$ & $0.54-0.57$ \\
\hline Hind leg & $\begin{array}{c}460-600 \\
(540)\end{array}$ & $\begin{array}{c}350-450 \\
(410)\end{array}$ & $\begin{array}{c}240-290 \\
(270)\end{array}$ & $\begin{array}{c}120-150 \\
(140)\end{array}$ & $0.69-0.77$ \\
\hline
\end{tabular}

Lengths are given as ranges and means (in parentheses).

racic horn; ratio of maximum diameter of plastron plate to length of corona 0.27-0.44. Respiratory atrium more or less amoeboid apically. Thoracic integument with elliptical dark field (Fig. 41) on median suture.

Abdomen: Shagreen (Fig. 42) mainly consisting of bifid and multifid spinules on tergites I-VIII, simple spinules on tergite IX. Segments I-VI each with 2 pairs of flattened L-setae; $\mathrm{L}_{1}$-seta on segment IV (Fig. 43) 138-155 $\mu \mathrm{m}$ long and 0.28-0.36 times of segment length. Segment VII with 4 pairs of lateral taeniae on about posterior half, and segment VIII with 5 pairs of lateral taeniae on about posterior half (Fig. 44). Anal lobe 365-450 $\mu \mathrm{m}$ long and 2.0-2.3 times as long as broad. Male genital sac 0.61-0.69 times as long as anal lobe.

Fourth instar larva $(\mathrm{n}=3$, unless otherwise stated).

Coloration: Head and claws of posterior parapod yellow and body yellowish- 

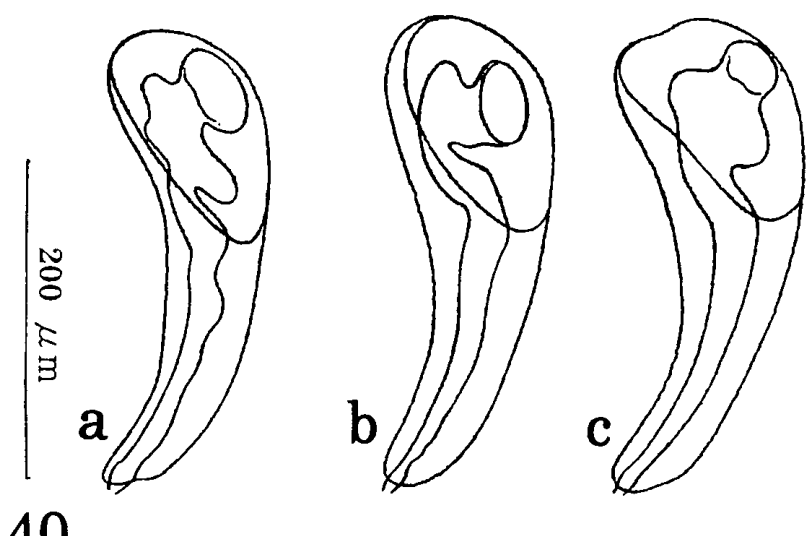

40
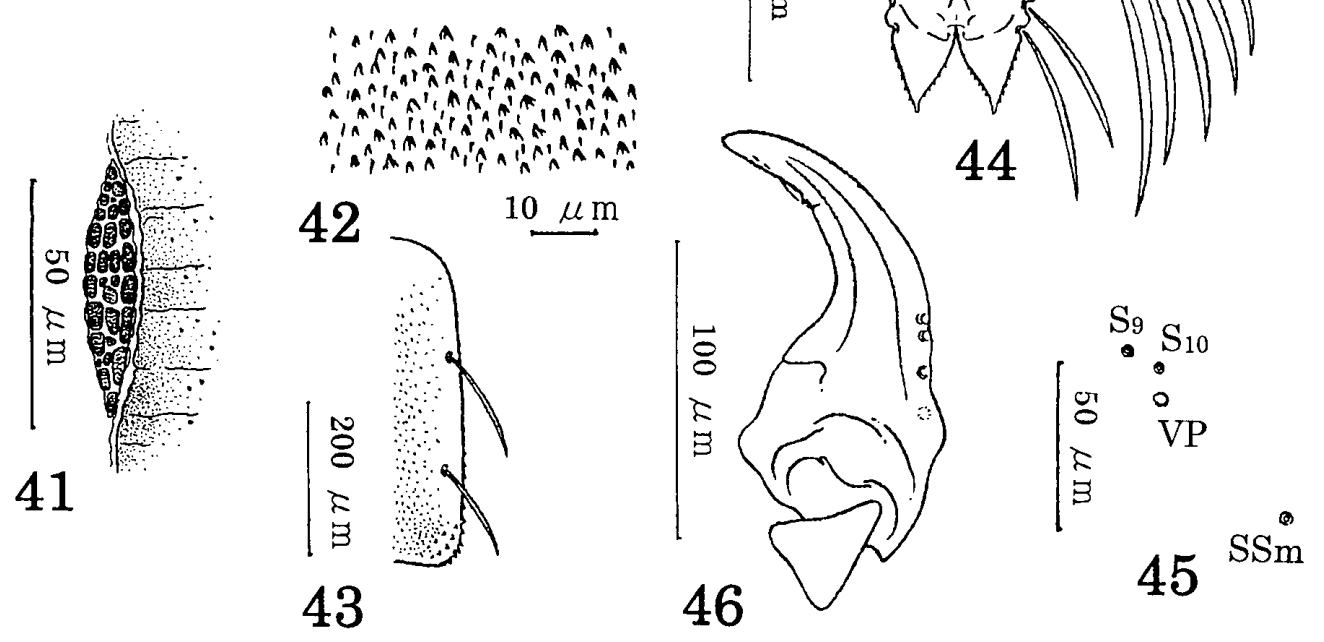

Figs 40-46. Conchapelopia togamaculosa Sasa and Okazawa, 1992, pupal exuviae, SUM-IC-T 0121 (40a), 0123 (40b), 0124 (40c), 0142 (41-44), and larval exuviae, SUM-IC-T 0123 (45, 46). 40a-c, Thoracic horn, showing morphological variation; 41, elliptical dark field on thoracic median suture; 42, shagreen on posteromedial part of abdominal tergite IV; 43, L-setae on abdominal segment IV; 44, abdominal segments VII-IX, dorsal view (only right lateral setae shown); 45, arrangement of ventral cephalic setae and sensory pore; 46, mandible. Abbreviations as in Figs 7-13.

white in life.

Head: Length $740-750 \mu \mathrm{m}$; cephalic index $0.55-0.57$. Dorsal cephalic seta $\mathrm{S}_{8}$ lateral to dorsal sensory pore and close to $S_{7}$; ventral cephalic seta $S_{10}$ posteromedial to $S_{9}$ and directly anterior to ventral sensory pore (Fig. 45). Lengths of antennal segments I-IV (in $\mu \mathrm{m}$ ) 250-265 (258), 48-50 (49), 6-8 (7), and 5-6 (6), respectivly; antennal ratio 4.1-4.2. Antennal segment I 9.6-11.4 times as long as its basal width, with ring organ positioned $0.29-0.30$ of way from apex; blade $58 \mu \mathrm{m}$ long, almost 5 times as long as its basal ring, extending beyond apex of segment III; accessory blade almost as long as blade. Antennal segment II 9.5-10.0 times as long as its basal width; style $10 \mu \mathrm{m}$ long, reaching to middle of segment IV; Lauterborn organ $5 \mu \mathrm{m}$ long. Mandible (Fig. 46) $125-145 \mu \mathrm{m}$ long. Basal segment of maxillary palp $50 \mu \mathrm{m}$ long, 3.6 times as long as its basal width, with ring organ positioned 0.20 of way from apex. M-appendage with 7 rows of granules on pseudoradula. Ligula $95 \mu \mathrm{m}$ long and almost twice as long as its broadest width. Paraligula bifid and 
43-45 $\mu \mathrm{m}$ long; fork positioned at about mid length. Pecten hypopharyngis with 17-19 teeth on each side.

Body: Procercus 4.2 times as long as wide, with 7 anal setae.

Distribution. Japan (Fukushima, Kanagawa, Shizuoka, and Toyama Prefectures).

Remarks. In the original description of Conchapelopia togamaculosa, Sasa and Okazawa (1992: 209) described "wings with numerous macrotrichia but without dark marks." After reexamination of the holotype, it has become evident that the wing is provided with three transverse bands formed by brown setae.

Dark-banded wings also occur in Conchapelopia pallidula (Meigen, 1818), C. triannulata (Goetghebuer, 1921), C. cygnus, C. trifascia, C. falcistylus, C. insolens, $C$. hittmairorum Michiels and Spies, 2002, and C. amamiaurea, as well as C. togamaculosa. Among these species, dark-ringed femora occur in $C$. cygnus, $C$. trifascia, $C$. falcistylus, $C$. insolens, and $C$. amamiaurea, and the presence of a digitiform appendage on the hypopygial median volsella is known in $C$. cygnus and $C$. insolens. The males of $C$. pallidula and $C$. hittmairorum lack any ventral lobes on the median volsella. Consequently, $C$. togamaculosa most closely resembles $C$. triannulata in the adult features. The male of $C$. togamaculosa, however, differs from that of $C$. triannulata in its hypopygial median volsella with a distinctly projecting basolateral corner, partially expanded dorsolateral processes, and a rather small ventral lobe (ratio of the ventral lobe length to the median volsella length 0.13-0.24). According to Michiels and Spies (2002), the median volsella of $C$. triannulata has a rounded basolateral corner and a relatively large ventral lobe (ratio of the ventral lobe length to the median volsella length about 0.7 ), and all of the dorsolateral processes gradually taper towards their apices. Also, the pupa of $C$. togamaculosa differs from that of $C$. triannulata (see Michiels and Spies 2002) in the relatively slender thoracic horn (length/width $2.6-3.4$ vs $2.0-2.2$ ) and the relatively small plastron plate (maximum diameter/coronal length $0.27-0.44$ vs more than $0.70)$.

The pupa of Conchapelopia togamaculosa appears unique in having an elliptical dark field on the thoracic median suture and relatively long L-setae on abdominal segments II-VI.

Conchapelopia togapallida Sasa and Okazawa, 1992 [Japanese name: Eri-torafu-yusurika]

(Figs 47-60, Table 6)

Conchapelopia togapallida Sasa and Okazawa, 1992: 209.

Material examined. Holotype of Conchapelopia togapallida: $\$$ (NSMT-I-Dip 4750), labeled " No. A 188: 16", Toga River in Toga Village, Toyama Prefecture, 5 July 1990. Non-types: 1 larva (SUM-IC-T 0163), small stream in Miyagase, Kiyokawa Village, Kanagawa Prefecture, 19 August 1992; 10 (SUM-IC-T 0164), same locality, 11 June 1995; 4oे, 1\%, with all their pupal exuviae (SUM-IC-T 0165-0169), small stream in Shiraiwa, Iwaki City, Fukushima Prefecture, 27 March 1996 (adults emerged on 1-8 April 1996); 1 \% with its pupal and larval exuviae (SUM-IC-T 0170), Asami River in Hirono Town, Fukushima Prefecture, 30 March 2002 (adult 
emerged on 26 April 2002); 1 pupal exuviae (SUM-IC-T 0171), small stream in Ikawa, Shizuoka City, Shizuoka Prefecture, 4 May 1998; 1 \% with its pupal and larval exuviae (SUM-IC-T 0172), fontal stream in Udo Hills, Ôya, Shizuoka City, 10 May 2000 (adult emerged on 16 May 2000); 3o $\delta, 1$ i, 1 larva, with all the adults' pupal exuviae and 3 of their larval exuviae (SUM-IC-T 0173-0177), same locality, 19 October 2000 (adults emerged on 22-24 October 2000); $20^{\star}{ }^{*}, 1 \%, 1$ pupa, 8 larvae, with all the adults' pupal exuviae and 3 of their larval exuviae (SUM-IC-T 0162, 0178-0188), same locality, 10 May 2001 (adults emerged on 16-23 May 2001); $20^{\star} \sigma^{*}, 9$ 9 , 5 pupae, 19 larvae, with 10 of their pupal exuviae and 11 of their larval exuviae (SUM-IC-T 0189-0223), same locality, 5 July 2001 (adults emerged on 12-25 July 2001).

Description. Male ( $\mathrm{n}=12$, unless otherwise stated). Body length 2.4-3.2 mm.

Coloration: Body entirely pale yellow, but abdominal tergite VII broadly darkened in some specimens. Wings without markings. Legs pale yellow.

Head: Temporals 13-19, uniserial, partly biserial. Antenna with apical seta 45-62 $\mu \mathrm{m}$ long; antennal ratio 1.2-1.6. Clypeus rounded, with 14-24 setae. Lengths of palpomeres 1-5 (in $\mu \mathrm{m}, \mathrm{n}=10)$ 50-68 (56), 60-100 (83), 125-180 (147), 145-193 (177), and 220-310 (272), respectively.

Thorax: Antepronotum with 3-7 lateral setae on each lobe. Scutal tubercle $5-10 \mu \mathrm{m}$ high. Acrostichals 39-58, biserial between median scutal vittae; dorsocentrals 15-28, medially uniserial, anteriorly and posteriorly bi- or triserial; humerals 5-13; prealars 8-16, uniserial, partly multiserial; 1 supraalar; no preepisternals. Scutellum with 18-27 setae. Wings (Fig. 47) $1.7-2.4 \mathrm{~mm}$ long; venarum ratio 0.86-0.92; squama with 18-29 setae. All legs with long tibial spurs each bearing 7-9 lateral teeth; ratio of inner spur length to outer spur length 1.0-1.1 in middle leg, 1.4-1.6 in hind leg; hind leg with tibial comb of 5-7, usually 6, spines. Tarsal beard moderately long; bristle ratio 4.4-6.6 in foreleg, 4.7-6.5 in middle leg, 5.0-6.5 in hind leg; tarsal brush absent. All tarsal claws pointed apically, and each with 1 long and several short spines basoventrally; pulvilli absent. Lengths and ratios of leg segments as shown in Table 6.

Hypopygium (Fig. 48): Tergite IX with 9-17 setae, many of them concentrated posterolaterally; lateral tubercle indistinct. Gonocoxite 108-148 $\mu \mathrm{m}$ long, with 4-6, usually 4, large preapical setae. Median volsella (Fig. 49) 60-85 $\mu \mathrm{m}$ long, rounded at basolateral corner, with 11-18 partially expanded dorsolateral processes along almost entire length and with 2 or 3 gradually tapering apical processes; pubescent ventral lobe large, 0.37-0.54 times as long as median volsella; basolateral digitiform appendage absent.

Female ( $\mathrm{n}=14$, unless otherwise stated). Body length $1.9-2.8 \mathrm{~mm}$.

Coloration: Entirely pale yellow.

Head: Temporals 15-22 in number. Antenna with apical seta $43-60 \mu \mathrm{m}$ long; terminal flagellomere almost as long as or slightly shorter than preceding 3 flagellomeres together; antennal ratio 0.22-0.30. Clypeus with 17-26 setae. Lengths of palpomeres 1-5 (in $\mu \mathrm{m}, \mathrm{n}=12$ ) 50-75 (61), 75-105 (88), 125-170 (149), 150-205 (179), and 223-318 (273), respectively.

Thorax: Antepronotum with 1-4 lateral setae on each lobe. Scutal tubercle 8-13 $\mu \mathrm{m}$ high. Acrostichals 50-71 in number, dorsocentrals 17-32, humerals 11-26, prealars 11-20, supraalars 1-2 (usually 1), no preepisternals. Scutellum with 25-35 setae. Wings $1.7-2.2 \mathrm{~mm}$ long; venarum ratio $0.84-0.93$; squama with $13-24$ setae. All legs with tibial spurs each bearing 69 lateral teeth; ratio of inner spur length to 

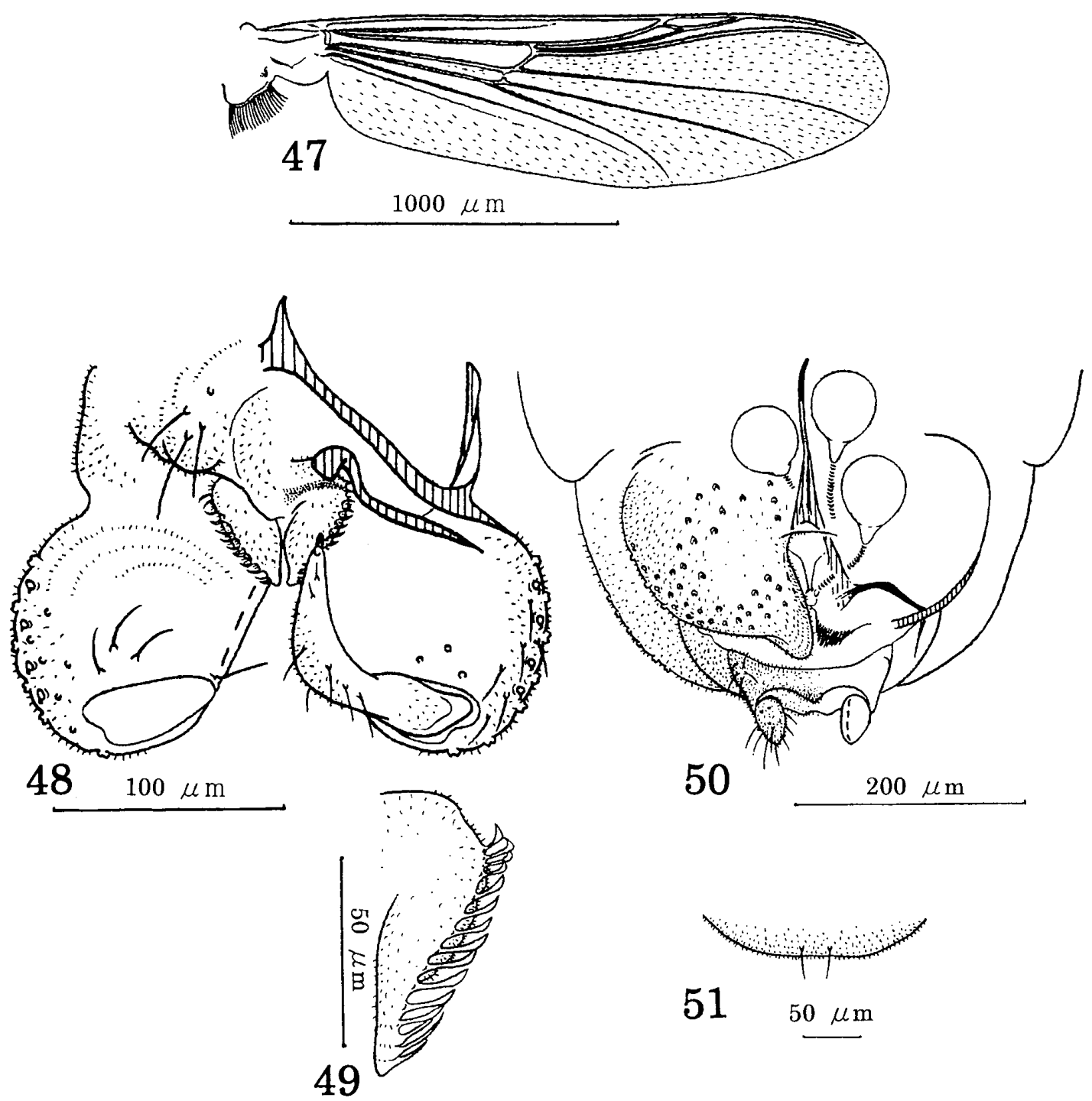

Figs 47-51. Conchapelopia togapallida Sasa and Okazawa, 1992, adult males, SUM-IC-T 0162 (47, 48), 0189 (49), and adult female, SUM-IC-T0190 (50, 51). 47, Wing; 48, hypopygium, dorsal view; 49, median volsella, dorsal view; 50, genitalia, ventral view; 51, gonotergite IX, dorsal view.

outer spur length 1.0-1.2 in middle leg, 1.4-1.5 in hind leg. All tarsal claws pointed apically, each with 1 long and several short spines basoventrally; pulvilli absent. Lengths and ratios of leg segments as shown in Table 6.

Genitalia (Fig. 50): Gonotergite IX (Fig. 51) with 0-3 setae. Labium with apical microtrichia. Seminal capsule pale, oval, $65-78 \mu \mathrm{m}$ long and $55-73 \mu \mathrm{m}$ wide. Segment $\mathrm{X}$ with 1-7 setae on each side.

Pupa ( $\mathrm{n}=31$, unless otherwise stated). Body length $3.1-4.6 \mathrm{~mm}$.

Coloration: Exuviae pale yellow, with dark scar and apophyses on abdomen.

Cephalothorax: Thoracic horn (Fig. 52a-c) $223-285 \mu \mathrm{m}$ long and 2.8-3.9 times as long as broad. Plastron plate oval, ratio of its maximum diameter to length of thoracic horn $0.15-0.23$. Corona occupying apical $0.25-0.40$ of thoracic horn; ratio of 
Table 6. Lengths (in $\mu \mathrm{m}$ ) and ratios of leg segments in 12 males and 12 females of Conchapelopia togapallida Sasa and Okazawa, 1992.

\begin{tabular}{|c|c|c|c|c|c|}
\hline & Coxa & Trochanter & Femur & Tibia & Tarsomere 1 \\
\hline \multicolumn{6}{|l|}{ Male } \\
\hline Foreleg & $\begin{array}{c}150-260 \\
(210)\end{array}$ & $\begin{array}{c}130-180 \\
(150)\end{array}$ & $\begin{array}{c}690-980 \\
(870)\end{array}$ & $\begin{array}{c}800-1160 \\
(1040)\end{array}$ & $\begin{array}{c}660-950 \\
(840)\end{array}$ \\
\hline Middle leg & $\begin{array}{c}270-400 \\
(350)\end{array}$ & $\begin{array}{c}90-130 \\
(110)\end{array}$ & $\begin{array}{c}700-1010 \\
(910)\end{array}$ & $\begin{array}{c}670-970 \\
(870)\end{array}$ & $\begin{array}{c}400-520 \\
(480)\end{array}$ \\
\hline Hind leg & $\begin{array}{c}230-350 \\
(290)\end{array}$ & $\begin{array}{c}80-120 \\
(110)\end{array}$ & $\begin{array}{c}650-950 \\
(830)\end{array}$ & $\begin{array}{c}850-1300 \\
(1150)\end{array}$ & $\begin{array}{c}620-880 \\
(790)\end{array}$ \\
\hline \multicolumn{6}{|l|}{ Female } \\
\hline Foreleg & $\begin{array}{c}180-250 \\
(220)\end{array}$ & $\begin{array}{c}130-180 \\
(150)\end{array}$ & $\begin{array}{c}720-940 \\
(840)\end{array}$ & $\begin{array}{c}850-1170 \\
(1020)\end{array}$ & $\begin{array}{c}690-870 \\
(790)\end{array}$ \\
\hline Middle leg & $\begin{array}{c}300-370 \\
(340)\end{array}$ & $\begin{array}{c}100-120 \\
(110)\end{array}$ & $\begin{array}{c}760-1020 \\
(890)\end{array}$ & $\begin{array}{c}760-1070 \\
(920)\end{array}$ & $\begin{array}{c}450-570 \\
(510)\end{array}$ \\
\hline \multirow[t]{2}{*}{ Hind leg } & $\begin{array}{c}240-320 \\
(290)\end{array}$ & $\begin{array}{c}100-120 \\
(110)\end{array}$ & $\begin{array}{c}710-910 \\
(810)\end{array}$ & $\begin{array}{c}930-1330 \\
(1120)\end{array}$ & $\begin{array}{c}610-820 \\
(710)\end{array}$ \\
\hline & Tarsomere 2 & Tarsomere 3 & Tarsomere 4 & Tarsomere 5 & Leg ratio \\
\hline \multicolumn{6}{|l|}{ Male } \\
\hline Foreleg & $\begin{array}{c}310-470 \\
(410)\end{array}$ & $\begin{array}{c}220-320 \\
(290)\end{array}$ & $\begin{array}{c}170-240 \\
(210)\end{array}$ & $\begin{array}{c}100-150 \\
(130)\end{array}$ & $0.78-0.84$ \\
\hline Middle leg & $\begin{array}{c}190-250 \\
(230)\end{array}$ & $\begin{array}{c}150-190 \\
(170)\end{array}$ & $\begin{array}{c}120-160 \\
(140)\end{array}$ & $\begin{array}{c}80-100 \\
(100)\end{array}$ & $0.52-0.60$ \\
\hline Hind leg & $\begin{array}{c}310-470 \\
(420)\end{array}$ & $\begin{array}{c}240-370 \\
(330)\end{array}$ & $\begin{array}{c}180-240 \\
(220)\end{array}$ & $\begin{array}{c}100-140 \\
(120)\end{array}$ & $0.65-0.73$ \\
\hline \multicolumn{6}{|l|}{ Female } \\
\hline Foreleg & $\begin{array}{c}330-450 \\
(400)\end{array}$ & $\begin{array}{c}240-310 \\
(280)\end{array}$ & $\begin{array}{c}180-220 \\
(200)\end{array}$ & $\begin{array}{c}110-140 \\
(130)\end{array}$ & $0.72-0.85$ \\
\hline Middle leg & $\begin{array}{c}210-270 \\
(250)\end{array}$ & $\begin{array}{c}160-210 \\
(190)\end{array}$ & $\begin{array}{c}120-160 \\
(140)\end{array}$ & $\begin{array}{c}80-100 \\
(90)\end{array}$ & $0.53-0.59$ \\
\hline Hind leg & $\begin{array}{c}350-460 \\
(400)\end{array}$ & $\begin{array}{c}270-360 \\
(310)\end{array}$ & $\begin{array}{c}180-230 \\
(210)\end{array}$ & $\begin{array}{c}100-140 \\
(120)\end{array}$ & $0.60-0.66$ \\
\hline
\end{tabular}

Lengths are given as ranges and means (in parentheses).

maximum diameter of plastron plate to length of corona $0.50-0.67$. Respiratory atrium slender, somewhat swollen apically.

Abdomen: Shagreen (Fig. 53) dense, consisting of solitary and simple spinules. Segments I-VI each with 2 pairs of flattened L-setae; $\mathrm{L}_{1}$-seta on segment IV 38-50 $\mu \mathrm{m}$ long and 0.10-0.14 times of segment length. Segment VII with 3 pairs of lateral taeniae on about posterior 0.30 , and segment VIII with 5 pairs of lateral taeniae on about posterior 0.30 ; lateral taenia on segment VII shorter than half of segment length (Fig. 54). Segment VIII with posterolateral spines 13-20 $\mu \mathrm{m}$ long (Fig. 55). Anal lobe $265-340 \mu \mathrm{m}$ long and 1.7-2.1 times as long as broad. Male genital sac $0.66-0.71$ times as long as anal lobe.

Fourth instar larva $(\mathrm{n}=48$, unless otherwise stated). Body length $3.8-6.6 \mathrm{~mm}$.

Coloration: Head yellow with posterior dark band. Body yellowish-white with 
yellow claws on posterior parapod.

Head (Fig. 56): Length 530-600 $\mu \mathrm{m}$; cephalic index 0.62-0.66. Dorsal cephalic seta $S_{8}$ lateral to dorsal sensory pore and close to $S_{7}$; ventral sensory pore directly medial to ventral cephalic seta $S_{9}$ and posterior to $S_{10}$. Lengths of antennal segments I-IV (in $\mu \mathrm{m}, \mathrm{n}=14$ ) 195-208 (200), 40-45 (42), 6-7 (6), and 5-6 (5), respectively; antennal ratio 3.6-4.0 (Fig. 57). Antennal segment I 7.8-10.3 times as long as its basal width, with ring organ positioned $0.29-0.34$ of way from apex; blade $49-50 \mu \mathrm{m}$ long, 4.9-5.0 times as long as its basal ring and reaching to apex of segment III; accessory blade almost as long as blade. Antennal segment II 8.0-10.0 times as long as its basal width; style 8-10 $\mu \mathrm{m}$ long, reaching to middle of segment IV; Lauterborn organ 3-4 $\mu \mathrm{m}$ long. Mandible (Fig. 58) $113-125 \mu \mathrm{m}$ long. Basal segment of maxillary palp $40-45 \mu \mathrm{m}$ long, 3.2-3.8 times as long as its basal width, with ring organ positioned $0.19-0.25$ of way from apex. M-appendage with 7 or 8 rows of numerous granules on pseudoradula. Ligula (Fig. 59) $75-78 \mu \mathrm{m}$ long and almost twice as long as its broadest width. Paraligula bifid and 28-38 $\mu \mathrm{m}$ long; fork positioned $0.45-0.57$ of way from base. Pecten hypopharyngis with 17-22 teeth on each side.

Body: Procercus 3.1-3.6 times as long as wide, with 7 anal setae. Four anal tubules almost 4 times as long as wide, tapering to pointed apex (Fig. 60).

Distribution. Japan (Fukushima, Kanagawa, Shizuoka, and Toyama Prefectures).

Remarks. In the original description of Conchapelopia togapallida, Sasa and Okazawa (1992, fig. 5b) illustrated the hypopygial median volsella as unarmed in the basal half. However, reexamination of the holotype has shown that the volsella has 15 or 16 partially expanded dorsolateral processes along its entire length, including the basal half.

The male of Conchapelopia togapallida is similar to that of the European species C. viator (Kieffer, 1911) in that the wings and legs lack conspicuous markings and the hypopygial median volsella has a pubescent ventral lobe and a rounded basolateral corner. However, Conchapelopia togapallida is separable from the latter by the lack of pulvilli on the legs and partially expanded dorsolateral processes on the median volsella of the hypopygium. According to Michiels and Spies (2002), C. viator has relatively wide and plumose pulvilli on the legs, and all the dorsolateral processes of the median volsella gradually taper towards the apices.

The pupa of Conchapelopia togapallida appears unique in the genus in having dense abdominal shagreen composed of simple spinules only. In other known species of this genus, pupae have abdominal shagreen mainly consisting of bifid or multifid spinules (Fittkau and Murray 1986).

Conchapelopia amamiaurea Sasa, 1990

[Japanese name: Amami-torafu-yusurika]

(Fig. 61)

Conchapelopia amamiaurea Sasa, 1990a: 136.

Material examined. Holotype of Conchapelopia amamiaurea: ô (NSMT-I-Dip 4692), labeled “No. A179: 51”, Yakkachi River in Amami City, Amami-ohshima Is- 

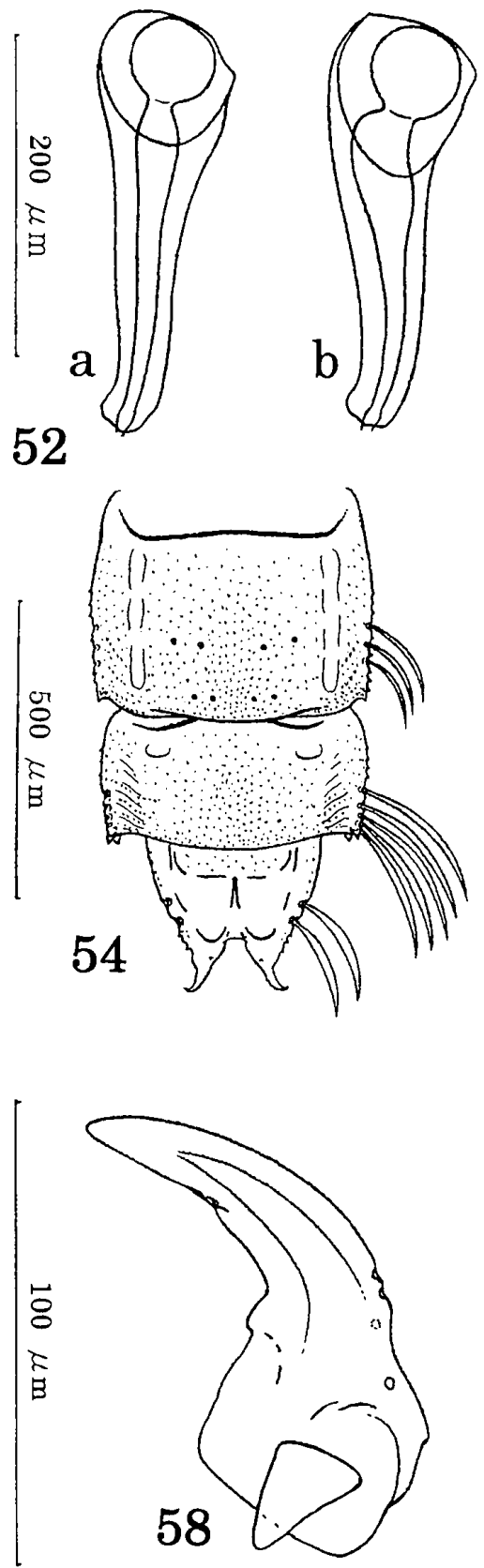
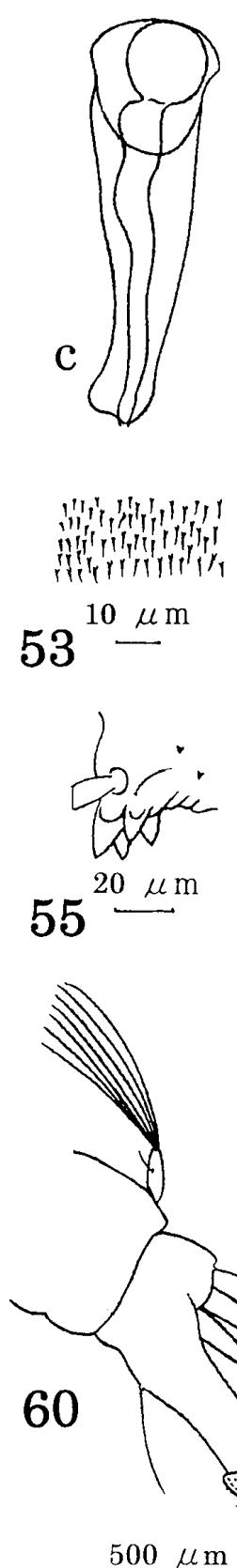
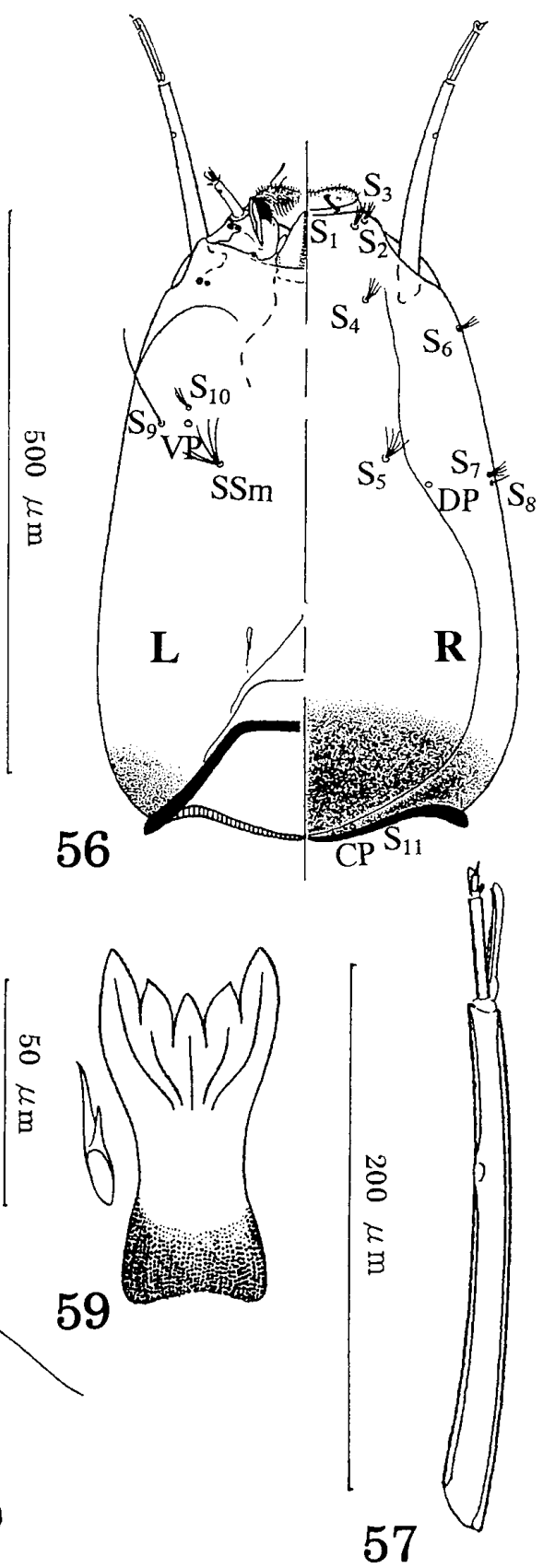

Figs 52-60. Conchapelopia togapallida Sasa and Okazawa, 1992, pupal exuviae, SUM-IC-T 0162 (52a, 53-55), 0169 (52b), 0194 (52c), and larval exuviae, SUM-IC-T 0162 (56), 0191 (57-60). 52a-c, Thoracic horn, showing morphological variation; 53, shagreen on posteromedial part of abdominal tergite IV; 54, abdominal segments VII-IX, dorsal view (only right lateral setae shown); 55, posterolateral spines on abdominal segment VIII; 56, head with chaetotaxy, dorsal view (R) and ventral view (L); 57, antenna; 58, mandible; 59, ligula and paraligula; 60, posterior body segments, lateral view. Abbreviations as in Figs 7-13. 
land, Kagoshima Prefecture, 18 March 1989.

Remarks. In the original description of Conchapelopia amamiaurea, Sasa (1990a) noted that the male is characterized by plain wings, high values of the foreand middle leg ratios (1.10-1.13 in the foreleg, 0.82-0.86 in the middle leg), and a hypopygial median volsella with gradually tapered dorsolateral processes along its entire length (see Sasa 1990a, fig. 24j). Reexamination of the holotype, however, has revealed that the original description is erroneous in the above points. The holotype of $C$. amamiaurea actually has dark-banded wings, much smaller leg ratios ( 0.84 in the foreleg, 0.62 in the middle leg), and partially expanded dorsolateral processes on the median volsella (Fig. 61).

Conchapelopia amamiaurea closely resembles $C$. pallidula in the adult morphology. Both species have a wing with transverse dark bands, a middle leg with a tarsal brush of strong setae, and a hypopygial median volsella with a triangularly projecting basolateral corner and with partially expanded dorsolateral processes along its entire length. Conchapelopia amamiaurea, however, differs from C. pallidula in the three-banded wing, the dark-ringed femur and tibia, and in having fewer partially expanded dorsolateral processes (about 10). In contrast, C. pallidula is characterized by wings each with two dark bands and one anal dark spot, entirely pale legs, and a hypopygial median volsella armed with about 20 partially expanded dorsolateral processes (Edwards 1929; Fittkau 1962; Michiels and Martin 2002).

Conchapelopia unzenalba Sasa, 1991

[Japanese name: Nagasaki-torafu-yusurika]

(Fig. 62)

Conchapelopia unzenalba Sasa, 1991: 90.

Conchapelopia tusimugehea Sasa and Suzuki, 1999: 108. Syn. nov.
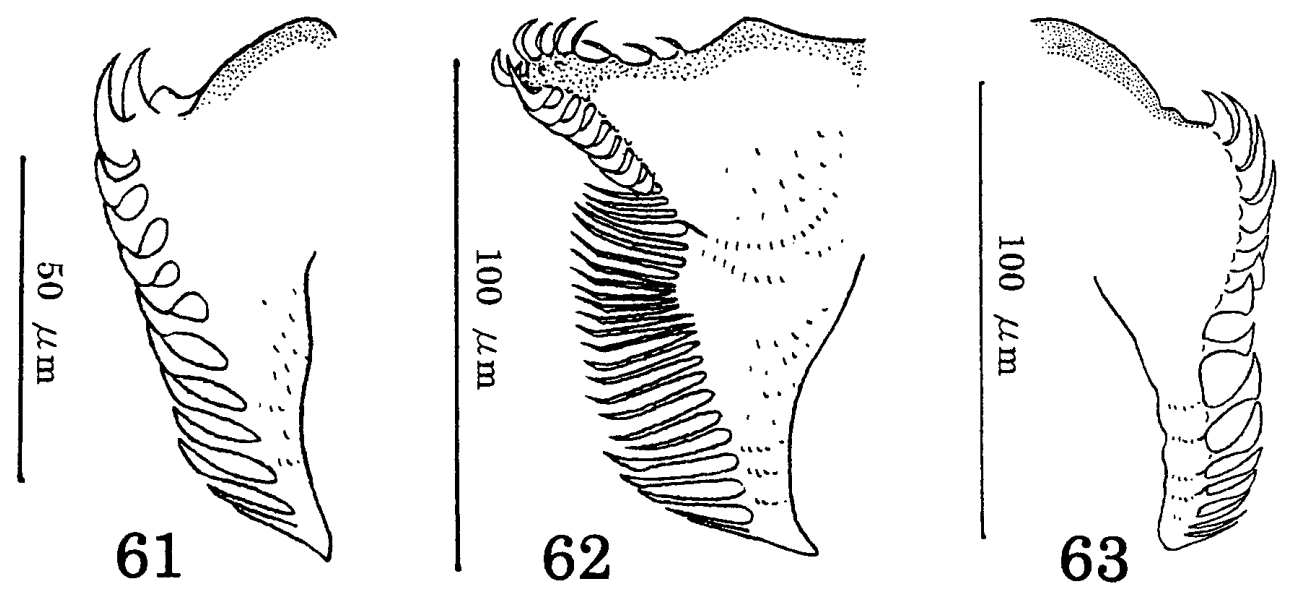

Figs 61-63. Median volsella of Conchapelopia spp. in dorsal view. 61, Conchapelopia amamiaurea Sasa, 1990, holotype, NSMT-I-Dip 4692; 62, Conchapelopia unzenalba Sasa, 1991, holotype, NSMT-I-Dip 4815; 63, Conchapelopia seiryusetea Sasa, Suzuki, and Sakai, 1998, holotype, NSMT-I-Dip 5201. 
Material examined. Holotype of Conchapelopia unzenalba: o (NSMT-I-Dip 4815), labeled "No. 205: 85", Unzen City, Nagasaki Prefecture, 8 November 1989. Holotype of Conchapelopia tusimugehea: ơ (NSMT-I-Dip 5170), labeled "No. 355: 48 (\#15: 3)", Tsushima City, Tsushima Islands, Nagasaki Prefecture, 26 March 1998.

Remarks. Sasa (1991) described Conchapelopia unzenalba based on a single male, which is characterized by the median volsella projecting triangularly at the basolateral corner and armed with tightly arranged dorsalateral processes along its entire length (Fig. 62). Later, Sasa and Suzuki (1999) described a new species, Conchapelopia tusimugehea, based on a single male, and illustrated its hypopygial median volsella as consisting of two, short and long, separated lobes (Sasa and Suzuki 1999, fig. 41i). However, reexamination of the holotype of C. tusimugehea has shown that the short lobe is a basal part of the median volsella, and the other features agree with those of $C$. unzenalba. Conchapelopia tusimugehea is undoubtedly a junior synonym of $C$. unzenalba. Reexamination of both of the holotypes has also shown that 11 or 12 large setal marks on the apex of the tarsomere 3 of middle legs were overlooked in the original descriptions.

Although a pubescent ventral lobe on the median volsella is an important discriminative feature with respect to related species (Michiels and Spies 2002), it was not mentioned in the original descriptions of $C$. unzenalba and C. tusimugehea. It is not clear whether $C$. unzenalba has a ventral lobe on the median volsella, because both holotypes are flattened on glass slides; however, the holotype of $C$. unzenalba has a slight ventral swelling on the median volsella, which may be a pubescent ventral lobe.

Conchapelopia unzenalba resembles C. rurika (Roback, 1957) in its plain wings, entirely pale middle leg with a tarsal brush of strong setae, and median volsella with a triangularly projected basolateral corner and tightly arranged dorsolateral processes. The hypopygial median volsella with ventrally curved and subapically expanded dorsolateral processes on the apical two thirds immediately distinguishes $C$. unzenalba from $C$. rurika. This feature of the dorsolateral process is more clearly recognizable in the holotype of $C$. tusimugehea than in the holotype of $C$. unzenalba because of the orientation of mounting. In contrast, $C$. rurika has almost straight and gradually tapered dorsolateral processes on the median volsella (Roback 1971, fig. 438).

Conchapelopia seiryusetea Sasa, Suzuki, and Sakai, 1998 [Japanese name: Seiryu-torafu-yusurika]

(Fig. 63)

Conchapelopia seiryusetea Sasa, Suzuki, and Sakai, 1998: 126.

Material examined. Holotype of Conchapelopia seiryusetea: o (NSMT-I-Dip 5201), labeled “No. 358: 52 (\#4: 12)", Shimanto River in Nakamura City, Kochi Prefecture, 26 April 1998.

Remarks. In the original description of Conchapelopia seiryusetea, Sasa et al. (1998, fig. 25i) showed a hypopygial median volsella with a long basolateral projection, which looks like a digitiform appendage. Reexamination of the holotype, however, has disclosed that the projection is not a basolateral digitiform appendage, 
but an anterior part of the phallapodeme. The median volsella actually lacks a basolateral digitiform appendage (Fig. 63). The authors did not mention a pubescent ventral lobe on the median volsella. In the holotype, it is not clear whether a pubescent ventral lobe is present or not because of the oblique compression of the specimen on its glass slide.

Conchapelopia seiryusetea appears closest to $C$. hittmairorum in that both species have entirely pale legs, a tarsal brush of strong setae on tarsomere 3 of the middle leg, and a hypopygial median volsella with a rounded basolateral corner and partially expanded dorsolateral processes along its entire length. It differs from $C$. hittmairorum in having plain wings; according to Michiels and Spies (2002), the latter species has dark-banded wings.

\section{Acknowledgements}

I am grateful to Dr Akihiko Shinohara of the National Museum of Nature and Science, Tokyo, for the loan of specimens in the Sasa collection. I also thank the editor and referees for their valuable comments.

\section{References}

Ashe, P. and Cranston, P. S. 1991. Family Chironomidae. Pp. 113-499. In: Soós, Á. and Papp, L. (Eds) Catalogue of Palaearctic Diptera 2. Akadémiai Kiadó, Budapest, 499 pp.

Chaudhuri, P. K., Hazra, N. and Alfred, J. R. B. 2001. A checklist of chironomid midges (Diptera: Chironomidae) of the Indian subcontinent. Oriental Insects 35: 335-372.

Edwards, F. W. 1929. British non-biting midges (Diptera, Chironomidae). Transactions of the Entomological Society of London 77: 279-430.

Epler, J. H. 2001. Identification Manual for the Larval Chironomidae (Diptera) of North and South Carolina. North Carolina Department of Environment and Natural Resources, Raleigh, and St. Johns River Water Management District, Palatka, 526 pp.

Fittkau, E. J. 1957. Thienemannimyia und Conchapelopia, zwei neue Gattungen innerhalb der Ablabesmyia-Costalis-Gruppe (Diptera: Chironomidae). Chironomidenstudien VII. Archiv für Hydrobiologie 53: 313-322.

Fittkau, E. J. 1962. Die Tanypodinae (Diptera: Chironomidae). Die Tribus Anatopyniini, Macropelopiini und Pentaneurini. Abhandlungen zur Larvalsystematik der Insekten 6: i-xi, 1-453.

Fittkau, E. J. and Murray, D. A. 1986. The pupae of Tanypodinae (Diptera: Chironomidae) of the Holarctic region-Keys and diagnoses. Entomologica Scandinavica, Supplement 28: $31-113$.

Fittkau, E. J. and Roback, S. S. 1983. The larvae of Tanypodinae (Diptera: Chironomidae) of the Holarctic region-Keys and diagnoses. Entomologica Scandinavica, Supplement 19: $33-110$.

Freeman, P. 1955. A study of the Chironomidae (Diptera) of Africa south of the Sahara. Part I. Bulletin of the British Museum (Natural History) 4: 1-67.

Hazra, N. and Chaudhuri, P. K. 2000. Coffmania, a new tanypod genus from the Darjeeling-Sikkim Himalayas, India (Diptera: Chironomidae). Annales de Limnologie 36: 169-179. 
Kobayashi, T. and Hayashi, F. 2001. Inter- and intraspecific variation in body size and scutal marking pattern in three species of Conchapelopia (Diptera: Chironomidae). Entomological Science 4: 39-45.

Kowalyk, H. E. 1985. The larval cephalic setae in the Tanypodinae (Diptera: Chironomidae) and their importance in generic determinations. Canadian Entomologist 117: 67-106.

Langton, P. H. 1984. A Key to Pupal Exuviae of British Chironomidae. P. H. Langton, March, Cambridgeshire, $324 \mathrm{pp}$.

Malloch, J. R. 1915. The Chironomidae, or midges, of Illinois, with particular reference to the species occurring in the Illinois River. Bulletin of the Illinois State Laboratory of Natural History 10: 275-543.

Michiels, S. and Spies, M. 2002. Description of Conchapelopia hittmairorum, spec. nov., and redefinition of similar western Palaearctic species (Insecta, Diptera, Chironomidae, Tanypodinae). Spixiana 25: 251-272.

Murray, D. A. 1976. Four new species of Conchapelopia Fittkau from Nepal with a discussion of the phylogeny of the nepalicola-group (Diptera: Chironomidae). Entomologica Scandinavica 7: 293-301.

Murray, D. A. 1995. Conchapelopia insolens, n. sp., a new species of Tanypodinae (Diptera: Chironomidae) from Sulawesi. Pp. 417-423. In: Cranston, P. S. (Ed.) Chironomids from Genes to Ecosystems. CSIRO Publications, East Melbourne, vi+482 pp.

Murray, D. A. and Fittkau, E. J. 1985. Hayesomyia a new genus of Tanypodinae from the Holarctic (Diptera, Chironomidae). Spixiana, Supplement 11: 195-207.

Murray, D. A. and Fittkau, E. J. 1989. The adult males of Tanypodinae (Diptera: Chironomidae) of the Holarctic region-Keys and diagnoses. Entomologica Scandinavica, Supplement 34: 37-123.

Oliver, D. R., Dillon, M. E. and Cranston, P. S. 1990. A Catalog of Nearctic Chironomidae. Research Branch, Agriculture Canada, Ottawa, $89 \mathrm{pp}$.

Roback, S. S. 1966. Notes on Tanypodinae types in European museums (Dipt.: Chironomidae). Entomological News 77: 113-132.

Roback, S. S. 1971. The adults of the subfamily Tanypodinae (=Pelopiinae) in North America (Diptera: Chironomidae). Monographs of the Academy of Natural Sciences of Philadelphia 17: $1-410$.

Roback, S. S. 1981. The immature chironomids of the Eastern United States V. Pentaneurini-Thienemannimyia group. Proceedings of the Academy of Natural Sciences of Philadelphia 133: 73-128.

Sæther, O. A. 1977. Female genitalia in Chironomidae and other Nematocera: morphology, phylogenies, keys. Bulletin of the Fisheries Research Board of Canada 197: 1-209.

Sæther, O. A. 1980. Glossary of chironomid morphology terminology (Diptera: Chironomidae). Entomologica Scandinavica, Supplement 14: 1-51.

Sæther, O. A., Ashe, P. and Murray, D. A. 2000. A.6. Family Chironomidae. Pp. 113-334. In: Papp, L. and Darvas, B. (Eds) Contributions to a Manual of Palaearctic Diptera (with Special Reference to Flies of Economic Importance). Appendix. Science Herald, Budapest, 604 pp.

Sasa, M. 1988. Studies on the chironomid midges collected from lakes and streams in the southern region of Hokkaido, Japan. Research Report from the National Institute for Environmental Studies 121: 9-76.

Sasa, M. 1990a. Studies on the chironomid midges (Diptera, Chironomidae) of the Nansei Islands, southern Japan. Japanese Journal of Experimental Medicine 60: 111-165.

Sasa, M. 1990b. On the chironomid midges of Jintsu River (Diptera, Chironomidae). Research 
Report from Toyama Prefectural Environmental Pollution Research Center [1990]: 29-67. Sasa, M. 1991. Studies on the chironomids of the Unzen area, Nagasaki. Research Report from Toyama Prefectural Environmental Pollution Research Center [1991]: 89-92.

Sasa, M. 1996. Seasonal distribution of the chironomid species collected with light traps at the side of two lakes in the Toyama City Family Park. Research Report from Toyama Prefectural Environmental Science Research Center [1996]: 16-112.

Sasa, M. 1998. Chironomidae of Japan. List of Species Recorded, and Supplemental Keys for Identification. Institute of Environmental and Welfare Studies, Kurobe City, Japan, 155 pp.

Sasa, M. and Kikuchi, M. 1995. Chironomidae (Diptera) of Japan. University of Tokyo Press, Tokyo, 333 pp.

Sasa, M. and Okazawa, T. 1991. The chironomids of the Joganji River and other places. Part 1. Studies on the chironomids of the Joganji River, Toyama (Diptera, Chironomidae). Research Report from Toyama Prefectural Environmental Pollution Research Center [1991]: 52-67.

Sasa, M. and Okazawa, T. 1992. Studies on the chironomid midges (yusurika) of Toga-mura, Toyama. Part 3. The subfamilies Diamesinae and Tanypodinae. Research Report from Toyama Prefectural Environmental Pollution Research Center [1992]: 205-230.

Sasa, M. and Suzuki, H. 1999. Studies on the chironomid midges of Tsushima and Iki Islands, western Japan. Part 2. Species of Orthocladiinae and Tanypodinae collected on Tsushima. Tropical Medicine 41: 75-132.

Sasa, M. and Suzuki, H. 2001a. Systematic studies on the species of Chironomidae recorded from Japan during the period from September 1997 to August 2000. Medical Entomology and Zoology 52: 1-9.

Sasa, M. and Suzuki, H. 2001b. Studies on the chironomid species collected in Hokkaido in September, 2000. Tropical Medicine 43: 1-38.

Sasa, M., Suzuki, H. and Sakai, T. 1998. Studies on the chironomid midges collected on the shore of Shimanto River in April 1998. Part 2. Description of additional species belonging to Orthocladiinae, Diamesinae and Tanypodinae. Tropical Medicine 40: 99-147.

Tokunaga, M. 1937a. Chironomidae from Japan (Diptera), IX. Tanypodinae and Diamesinae. Philippine Journal of Science 62: 21-65.

Tokunaga, M. 1937b. Nihon Dobutsu Bunrui (Fauna Nipponica). Vol. 10, Fasc. 7, No. 1. Family Chironomidae (1). Sanseido, Tokyo, 110 pp. [In Japanese]

Tokunaga, M. 1939. Chironomidae from Japan (Diptera), XI. New or little-known midges, with special reference to the metamorphoses of torrential species. Philippine Journal of Science 69: 297-345.

Wang, S. 1994. New and little-known Chironomidae (Diptera) from the southern provinces of China. Entomotaxonomia 16: 135-148. 